
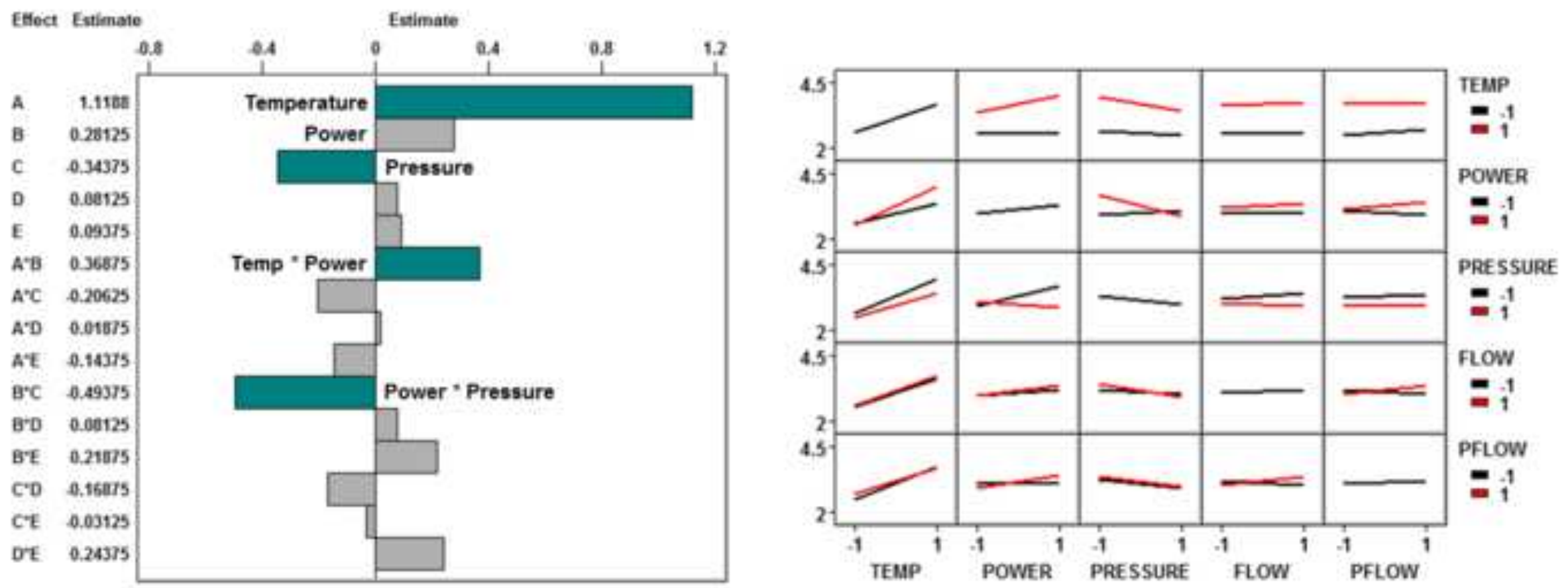


\title{
Tuning the Properties of a Complex Disordered Material: Full Factorial Investigation of PECVD-Grown Amorphous Hydrogenated Boron Carbide
}

\author{
Bradley J. Nordell ${ }^{a}$, Christopher L. Keck ${ }^{a}$, Thuong D. Nguyen ${ }^{a}$, A. N. Caruso ${ }^{a}$, Sudhaunshu S. Purohit ${ }^{b}$, \\ William A. Lanford ${ }^{c}$, Dhanadeep Dutta ${ }^{d \dagger}$, David Gidley ${ }^{d}$, Patrick Henry ${ }^{e}$, Sean W. King ${ }^{e}$, and Michelle \\ M. Paquette ${ }^{a, *}$ \\ ${ }^{a}$ Department of Physics and Astronomy, University of Missouri-Kansas City, Kansas City, MO 64110, \\ United States \\ ${ }^{b}$ Department of Chemistry, University of Missouri-Kansas City, Kansas City, MO 64110, United States \\ ${ }^{c}$ Department of Physics, University at Albany, Albany, NY 12222, United States \\ ${ }^{d}$ Department of Physics, University of Michigan, Ann Arbor, MI 48109, United States \\ ${ }^{e}$ Logic Technology Development, Intel Corporation, Hillsboro, OR 97124, United States \\ ${ }^{\dagger}$ Present address: Radiochemistry Division, Bhabha Atomic Research Centre, Trombay, Mumbai 400085, \\ India \\ *Corresponding author. E-mail address: paquettem@umkc.edu
}


Keywords: amorphous materials; chemical vapor deposition; thin films; dielectric properties 


\section{INTRODUCTION}

Recent decades have witnessed an explosion of new and complex materials vying for a role in upand-coming technologies, as well as next-generation technologies in need of perfectly tailored materials. Ambitious and coordinated materials characterization and design efforts, such as those envisioned by the Materials Genome Initiative [1,2], are needed to harness the full potential of twenty-first century materials science and efficiently match material with application. An example of a unique nanostructured material suitable as a case study for materials design efforts is amorphous hydrogenated boron carbide $\left(\mathrm{a}-\mathrm{B}_{x} \mathrm{C}: \mathrm{H}_{y}\right)$, which consists of a polymeric network of twelve-vertex icosahedral carborane units and hydrocarbon groups with varying degrees of cross-linking and hydrogenation [3]. As an amorphous material with unusual bonding [4,5], characterization and design efforts present additional challenges: the lack of available theory to adequately describe physical properties [6,7], the inability to experimentally determine or computationally model the atomic structure of disordered solids [8], and the near infinite number of configurations possible resulting from non-thermodynamic growth conditions [9]. Such challenges render coordinated characterization efforts even more important for $\mathrm{a}-\mathrm{B}_{x} \mathrm{C}: \mathrm{H}_{y}$ and similarly complex materials.

Thin-film $\mathrm{a}-\mathrm{B}_{x} \mathrm{C}: \mathrm{H}_{y}$ has been under growing consideration for various specialized technologies. As a boron-rich solid, it has a high cross-section for thermal neutron capture and is therefore of interest for nuclear applications ranging from reactor coatings [10,11] to neutron detection [12]. Its semi-insulating properties make it particularly appealing for solid-state direct-conversion neutron detectors [13-16], which have yet to achieve commercial potential but could show dramatic efficiency improvements over existing solutions. Its low- $Z$ character (i.e., low electron and mass density), coupled with its robust mechanical, chemical, and thermal properties, render it a candidate for low- $\kappa$ dielectric material development [17-19], a challenge at the forefront of modern integrated circuit interconnect technologies [20,21]. With the right combination of properties, $a-B_{x} C: H_{y}$ may additionally prove suitable for other specialized electronics [22,23] and coatings [24-27].

From an experimental perspective, significant groundwork must be laid to position a new material for widespread adoption. However, more often than not, such efforts lack sufficient direction and many years are required for applications to come to fruition. In the case of $\mathrm{a}-\mathrm{B}_{x} \mathrm{C}: \mathrm{H}_{y}$, dozens of materials growth and characterization studies have been published [28-47], but because these have covered such a wide range of growth methods and resulting a- $\mathrm{B}_{x} \mathrm{C}: \mathrm{H}_{y}$ variants, and because these typically only focus on one or a small number of process conditions or properties at a time, they fail to provide a comprehensive picture of the process-property landscape for this entire material family or any specific variant. One fabrication method that has gained traction, particularly for device applications, is the plasma-enhanced chemical vapor deposition (PECVD) of $\mathrm{a}-\mathrm{B}_{x} \mathrm{C}: \mathrm{H}_{y}$ using a single-source molecule-based ortho-carborane (o$\mathrm{C}_{2} \mathrm{~B}_{10} \mathrm{H}_{12}$ ) precursor [48-57]. We hypothesize that this process yields a more uniform material (due to the 
use of a single-source precursor), ultimately distinct from those produced using other common deposition methods such as sputtering from a $\mathrm{B}_{4} \mathrm{C}$ target or variations of CVD-based growth from gaseous precursors (e.g., $\mathrm{B}_{2} \mathrm{H}_{6}, \mathrm{BCl}_{3}, \mathrm{CH}_{4}$ ). By using a single-source precursor and varying PECVD process parameters, systematic tuning of material properties over a vast space is possible [58]. We aim to rigorously map the process-structure-property relationships in carborane-based a- $\mathrm{B}_{x} \mathrm{C}: \mathrm{H}_{y}$, while uncovering the underlying chemistry and physics.

A previous study by Nordell et al. looked at the effects of temperature and power on the growth of PECVD a- $\mathrm{B}_{x} \mathrm{C}: \mathrm{H}_{y}$ as well as the influence of hydrogen content on a wide range of material properties [58]. Here, we report an extension of this work, to include the effects of other major PECVD process parameters: pressure, total flow rate, and partial precursor pressure. To effectively map the effects of all five process parameters, we apply design of experiments (DOE) principles [59] and employ an $n^{k}$ twolevel $(n=2)$ five-factor $(k=5)$ full factorial experiment design (i.e., a $2^{5}$ design) [60-62]. This design comprises all unique combinations of each of the five process parameters at either a "low" $(-1)$ or a "high" (+1) value, and allows for a statistically sound evaluation of both the effect of each parameter as well as any interactions between parameters, while minimizing the number of growths required. In addition to investigating process effects, we tease out relationships between properties, and explore more nuanced correlations with chemical stoichiometry that become evident in the wider parameter space covered, notably the influence of carbon content. We anticipate that a characterization effort of this depth will be important not only in optimizing material properties for application, but in providing the largescale data sets needed to develop computational methods and physical theory for treating disordered solids.

\section{EXPERIMENTAL}

\subsection{Thin-Film Growth}

Amorphous hydrogenated boron carbide $\left(a-\mathrm{B}_{x} \mathrm{C}: \mathrm{H}_{y}\right)$ films were grown using a previously described [58] custom-built capacitively coupled plasma-enhanced chemical vapor deposition (PECVD) system with a single-source solid ortho-carborane $\left(\mathrm{C}_{2} \mathrm{~B}_{10} \mathrm{H}_{12}\right)$ precursor and $\mathrm{Ar}$ process gas. The ortho-carborane was purchased from Katchem and sublimed in vacuo before use. The argon gas was $99.9999 \%$ purity (Airgas, BIP, $<10 \mathrm{ppb} \mathrm{O}_{2},<20 \mathrm{ppb} \mathrm{H}_{2} \mathrm{O}$ ) and passed through additional in-line $\mathrm{O}_{2}$ and $\mathrm{H}_{2} \mathrm{O}$ filters to further reduce oxygen and water impurity levels to the hundreds-of-ppt range prior to introduction to the chamber. The ortho-carborane was introduced via a solid precursor 'bubbler' heated to $75{ }^{\circ} \mathrm{C}$ through which heated Ar gas was flowed prior to delivery to the chamber through a showerhead. The partial flow 

directly into the chamber, although the exact partial pressure of ortho-carborane in the Ar is not known.

\subsection{Factorial Experiment}

A $2^{5}$ full factorial experiment design was created using the low (-1) and high (+1) values summarized in Table 1. The ranges were chosen so as to stay within the operational limits of the PECVD system as well as to maintain the integrity of the PECVD growth. Five replicate center point (level " 0 ") growths were additionally included to independently assess error within the process in lieu of the more experimentally costly option of replicating each individual run. The conditions for each growth are summarized in Table 2. All films were grown for 12 minutes on a combination of $15 \times 15 \mathrm{~mm}$ silicon [1$15 \Omega \cdot \mathrm{cm}$ p-type $\mathrm{Si}(100)]$ and glass substrates. The order of the growths was randomized to mitigate any systematic variation.

\subsection{Thin-Film Characterization}

A detailed description of measurement and analysis methods can be found in Nordell et al [58]. Briefly, atomic concentrations $(\% \mathrm{~B}, \mathrm{C}, \mathrm{H}$, and $\mathrm{O})$ were determined by nuclear reaction analysis (NRA) methods. Thin-film density was also determined from NRA measurements and, on a subset of samples, by X-ray reflection (XRR) measurements. Hardness $(H)$ and Young's modulus $(E)$ were determined by nanoindentation (NI) experiments. Pore size was measured by positron annihilation lifetime spectroscopy (PALS) on selected samples. Thin-film thickness $(d)$, index of refraction $(n)$, and extinction coefficient $(k)$ were measured with a J.A. Woolam alpha-SE spectroscopic ellipsometer using a Cauchy model with a graded layer. The real part of the high-frequency $\left(4.6 \times 10^{14} \mathrm{~Hz} / 1.96 \mathrm{eV}\right)$ dielectric constant was calculated from the optical constants via $\varepsilon_{1}=n^{2}-k^{2}$. The absorption coefficients $(\alpha)$ for the a- $\mathrm{B}_{x} \mathrm{C}: \mathrm{H}_{y}$ films were determined by ultraviolet-visible (UV-vis) transmission spectroscopy measurements for thin films on glass substrates (transparent from 1.5-4 eV). The absorption coefficient as a function of energy was calculated using $T=I / I_{0}=\exp (-\alpha d)$, where $T$ is transmission, $I$ intensity of transmitted radiation, and $I_{0}$ intensity of incident radiation. From the absorption coefficient data, the Tauc optical band gap ( $\left.E_{\text {Tauc }}\right)$ and slope parameter $\left(B^{1 / n}\right)$ were determined using a Tauc analysis in the $\alpha>10^{4} \mathrm{~cm}^{-1}$ region based on the relationship $(\alpha \cdot E)^{n}=B\left(E-E_{\text {Tauc }}\right)$, with $n=2$. The isoabsorption gap, $E_{04}$, was also determined as the energy at which $\alpha$ reaches $1 \times 10^{4} \mathrm{~cm}^{-1}$. The Urbach energy $\left(E_{\mathrm{U}}\right)$ was determined from a fit to the exponential edge of the absorption coefficient data in the $10^{3} \leq \alpha \leq 10^{4} \mathrm{~cm}^{-1}$ region using the expression $\alpha(E)=\alpha_{0} \exp \left(-E / E_{\mathrm{U}}\right)$. Current-voltage $(I V)$ and $100 \mathrm{kHz}$ capacitance-voltage $(C V)$ measurements were obtained on metal-insulator-semiconductor a- $\mathrm{B}_{x} \mathrm{C}: \mathrm{H}_{y} / \mathrm{Si}$ heterostructures using a mercury probe with Keithley 2400 source meter (voltage source), 6485 picoammeter (current sensor), and $590 \mathrm{CV}$ analyzer. 
The low-frequency (i.e., the total) dielectric constant $(\kappa)$ was determined from the $C V$ curve in the accumulation region through the geometric capacitance relationship for an MIS capacitor, $\kappa=C d / \varepsilon_{0} A$, where $\varepsilon_{0}$ is the permittivity of free space and $A$ the area of the $\mathrm{Hg}$ contact. Electrical resistivity $(\rho)$ was determined from the $I V$ curve in the Ohmic regime $\left(I \propto V^{n} ; n \approx 1\right)$ from Ohm's law, $\rho=V A / I d$. Mobility $(\mu)$ was calculated using Murgatroyd's field-dependent treatment of Child's Law in the space-chargelimited current regime of the $I V$ curve $\left.\left(I \propto V^{n} ; n \approx 2\right), I=(9 / 8) \kappa \varepsilon_{0}\left(V^{2} / d^{2}\right) \mu_{0} \exp \left[0.89 \gamma(V / d)^{1 / 2}\right)\right]$, following the protocol outlined by Blakesley et al $[63,64]$. Here, $\mu_{0}$ is the zero-field mobility and $\gamma$ a factor defining field-dependence, and from these values the field-dependent mobility (reported here at $0.1 \mathrm{MV} / \mathrm{cm}$ ) can be determined via $\mu_{\mathrm{F}}=\mu_{0} \exp \left[\gamma(V / d)^{1 / 2}\right]$. Free charge carrier concentration (n) was also determined from the resistivity and mobility values via $\rho=1 /(\mathrm{e} n \mu)$, where $e$ is the fundamental charge. With the exception of NI, XRR, and PALS analysis, all measurement techniques were applied to all samples if possible. In a few cases, measurements could not be completed because of either insufficient film thickness, delamination prior to measurement, or electrical instability/breakdown.

Table 1. Process parameter (factor) levels for the $2^{5}$ full factorial DOE for the PECVD growth of thinfilm a-B ${ }_{x} \mathrm{C}: \mathrm{H}_{y}$.

\begin{tabular}{lccccc}
\hline Factor & Code & Units & Low $(-1)$ & High $(+\mathbf{1})$ & Center (0) \\
\hline Temperature & $\mathrm{A}$ & ${ }^{\circ} \mathrm{C}$ & 100 & 450 & 275 \\
\hline Power & $\mathrm{B}$ & $\mathrm{W}$ & 10 & 40 & 20 \\
\hline Pressure & $\mathrm{C}$ & Torr & 0.2 & 4 & 2 \\
\hline Flow Rate & $\mathrm{D}$ & $\mathrm{sccm}$ & 50 & 100 & 75 \\
\hline Partial Flow Rate & $\mathrm{E}$ & $\mathrm{N} / \mathrm{A}$ & 0.1 & 0.5 & 0.3 \\
\hline
\end{tabular}


Table 2. Process parameter matrix and resulting properties (responses) for the a- $\mathrm{B}_{x} \mathrm{C}: \mathrm{H}_{y}$ samples produced in the $2^{5}$ full factorial DOE.

\begin{tabular}{|c|c|c|c|c|c|c|c|c|c|c|c|c|c|c|c|c|c|c|c|c|c|c|c|}
\hline $\begin{array}{l}\text { Film } \\
\text { no. }\end{array}$ & $\mathbf{A}$ & B & $\mathrm{C}$ & D & $\mathbf{E} \quad \begin{array}{c}d \\
(\mathbf{n m})\end{array}$ & $\begin{array}{c}\text { Growth } \\
\text { rate } \\
(\mathbf{n m} / \mathbf{m i n})\end{array}$ & $\mathrm{B} / \mathrm{C}$ & $\begin{array}{c}\text { At. } \% \\
\text { O }\end{array}$ & $\begin{array}{c}\text { At. } \% \\
\text { H }\end{array}$ & $\begin{array}{c}\text { Density } \\
\left(\mathrm{g} / \mathrm{cm}^{3}\right) \\
(\mathrm{RBS} / \mathrm{XRR})\end{array}$ & $\begin{array}{c}E \\
(\mathbf{G P a})\end{array}$ & $\begin{array}{c}\boldsymbol{H} \\
(\mathbf{G P a})\end{array}$ & $\begin{array}{c}\text { Pore } \\
\text { diam. } \\
(\mathbf{n m})\end{array}$ & $\varepsilon_{1}$ & $\boldsymbol{\kappa}$ & $\kappa-\varepsilon_{1}$ & $\begin{array}{c}E_{\mathrm{g}} \\
(\mathrm{eV})\end{array}$ & $\begin{array}{c}E_{04} \\
(\mathrm{eV})\end{array}$ & $\begin{array}{c}E_{\mathrm{U}} \\
(\mathrm{meV})\end{array}$ & $\begin{array}{c}B^{1 / 2} \\
m \cdot e V)^{-1 / 2}\end{array}$ & $\begin{array}{c}\rho \\
(\boldsymbol{\Omega} \cdot \mathbf{c m})\end{array}$ & $\begin{array}{c}\mu_{\mathrm{F}} @ 0.1 \\
\mathrm{MV} / \mathrm{cm} \\
\left(\mathrm{cm}^{2} / \mathbf{V} \cdot \mathbf{s}\right)\end{array}$ & $n\left(\mathrm{~cm}^{-3}\right)$ \\
\hline N1 & -1 & -1 & -1 & -1 & -1427 & 36 & 3.8 & 4 & 46 & $0.78 / 1.5$ & - & - & 0.68 & 2.1 & 3.2 & 1.1 & 3.6 & 4.0 & 267 & 12 & - & - & - \\
\hline $\mathrm{N} 2$ & 1 & -1 & -1 & -1 & -1620 & 52 & 4.5 & 4 & 34 & 1.29 & - & - & - & 3.2 & 3.9 & 0.7 & 3.6 & 3.6 & 304 & 997 & $8.1 \times 10^{13}$ & $1.2 \times 10^{-11}$ & $6.3 \times 10^{14}$ \\
\hline $\mathrm{N} 3$ & -1 & 1 & -1 & -1 & -1322 & 27 & 3.4 & 7 & 42 & $1.09 / 1.5$ & - & - & - & 2.8 & 3.8 & 1.0 & 3.6 & 4.1 & 283 & 1203 & $6.3 \times 10^{11}$ & - & - \\
\hline $\mathrm{N} 4$ & 1 & 1 & -1 & -1 & -1452 & 38 & 4.0 & 0 & 21 & 1.43 & 206 & 15 & $<0.3$ & 4.8 & 5.0 & 0.2 & 2.0 & 2.4 & 727 & 178 & $4.9 \times 10^{13}$ & $1.0 \times 10^{-10}$ & $1.3 \times 10^{15}$ \\
\hline N5 & -1 & -1 & 1 & -1 & -1366 & 31 & 4.5 & 4 & 44 & 1.11 & 20 & 1 & - & 2.8 & 3.6 & 0.8 & - & - & - & - & $1.2 \times 10^{13}$ & $2.7 \times 10^{-10}$ & $2.0 \times 10^{15}$ \\
\hline N6 & 1 & -1 & 1 & -1 & -1364 & 30 & 4.7 & 0 & 28 & 1.69 & 162 & 14 & - & 4.5 & 4.9 & 0.4 & 2.7 & 3.2 & 550 & 274 & $7.4 \times 10^{13}$ & - & - \\
\hline $\mathrm{N} 7^{a}$ & -1 & 1 & 1 & -1 & $-1 \quad 13$ & 1 & - & - & - & - & - & - & - & 2.1 & - & - & 3.7 & 4.0 & 219 & 1575 & $1.2 \times 10^{13}$ & $5.4 \times 10^{-12}$ & $9.6 \times 10^{16}$ \\
\hline N8 & 1 & 1 & 1 & -1 & -161 & 5 & 2.9 & 12 & 30 & 143 & - & - & - & 3.1 & 3.8 & 0.7 & 3.7 & 3.8 & 200 & 1675 & - & - & - \\
\hline N9 & -1 & -1 & -1 & 1 & -1571 & 48 & 4.2 & 3 & 42 & & 16 & 1 & 0.73 & 2.7 & 3. & 1.0 & 3. & 4.1 & 255 & 1061 & $2.6 \times 10^{13}$ & $2.3 \times 10^{-10}$ & $1.0 \times 10^{15}$ \\
\hline N10 & 1 & -1 & -1 & 1 & -1515 & 43 & 4.3 & 4 & 35 & 1 & - & - & - & 3.4 & 3. & 0.4 & 3. & 3.5 & 295 & 1041 & $1.2 \times 10^{12}$ & $8.6 \times 10^{-10}$ & $6.1 \times 10^{15}$ \\
\hline N11 & -1 & 1 & -1 & 1 & -1450 & 38 & 3.9 & 7 & 43 & 1.11 & 9 & 1 & - & 2.8 & 3. & 0.9 & 3. & 3.5 & 281 & 1105 & $3.6 \times 10^{13}$ & $1.6 \times 10^{-10}$ & $1.1 \times 10^{15}$ \\
\hline N12 & 1 & 1 & -1 & 1 & -1430 & 36 & 4.0 & 1 & 25 & 1.55 & 207 & 16 & - & 4.2 & 4.9 & 0.7 & 3.2 & 3.0 & 459 & 540 & $1.1 \times 10^{13}$ & - & - \\
\hline N13 & -1 & -1 & 1 & 1 & -1142 & 12 & 3.5 & 5 & 42 & 1.02 & 33 & 2 & - & 2.7 & 3.6 & 0.9 & 3. & 4.0 & 20 & 1365 & - & - & - \\
\hline N14 & 1 & -1 & 1 & 1 & -1328 & 27 & 4.0 & 3 & 35 & 1.19 & - & - & - & 3.1 & 3. & 0.5 & 3 & 3.7 & 32 & 660 & $1.3 \times 10^{12}$ & - & - \\
\hline $\mathrm{N} 15^{b}$ & -1 & 1 & 1 & 1 & -139 & 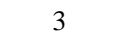 & - & - & - & - & - & - & - & & 2. & & & & & 2200 & - & - & - \\
\hline N16 & 1 & 1 & 1 & 1 & -142 & 4 & 3.1 & 5 & 20 & $2 /$ & - & - & $<0.3$ & & 4 & & & & & 1082 & $4.4 \times 10^{14}$ & $4.6 \times 10^{-14}$ & $3.1 \times 10^{17}$ \\
\hline N17 & -1 & -1 & -1 & -1 & 1770 & 64 & 4.2 & 4 & 41 & & - & - & & & 4 & & & & 2 & 1127 & $9.3 \times$ & $6 \times$ & $4.1 \times 10^{14}$ \\
\hline $\mathrm{N} 18$ & 1 & -1 & -1 & -1 & 1930 & 7 & 4.9 & 5 & 3 & & - & - & - & 3. & 3. & & 3. & & 38 & 3 & $6.7 \times$ & $1.9 \times 10^{-11}$ & $5.0 \times 10^{15}$ \\
\hline N19 & -1 & 1 & -1 & -1 & 1633 & 53 & 4.2 & 5 & 40 & 1. & 14 & 1 & 0.67 & 2.8 & 3.5 & 1. & 3. & 3.7 & 26 & 1082 & $4.3 \times 10^{13}$ & $3.7 \times 10^{-10}$ & $4.0 \times 10^{14}$ \\
\hline $\mathrm{N} 20$ & 1 & 1 & -1 & -1 & 1547 & 46 & 4.7 & 0 & 27 & 1.4 & 146 & 11 & - & 4.0 & 4.1 & 0.1 & 2. & 3.2 & 56 & 311 & $1.6 \times 10^{15}$ & $1.0 \times 10^{-12}$ & $3.8 \times 10^{15}$ \\
\hline $\mathrm{N} 21$ & -1 & -1 & 1 & -1 & 1124 & 10 & 2.8 & 6 & 40 & & - & - & 0.71 & 2.5 & 3. & 0.8 & 3. & 4.1 & 210 & 1665 & $5.8 \times 10^{12}$ & - & - \\
\hline $\mathrm{N} 22$ & 1 & -1 & 1 & -1 & 1485 & 40 & 4.2 & 3 & 36 & 1.22 & - & - & - & 3.1 & 3.8 & 0.7 & 3.5 & 3.7 & 370 & 490 & $5.7 \times 10^{14}$ & $6.4 \times 10^{-12}$ & $1.7 \times 10^{15}$ \\
\hline $\mathrm{N} 23$ & -1 & 1 & 1 & -1 & 182 & 7 & 3.1 & 5 & 41 & 1.1 & 24 & 3 & - & 2.7 & 3. & 0.9 & 3. & 3.9 & 21 & 1540 & $2.2 \times$ & $5.9 \times 10^{-12}$ & $4.8 \times 10^{16}$ \\
\hline $\mathrm{N} 24$ & 1 & 1 & 1 & -1 & 1173 & 14 & 3.5 & 3 & 34 & $1.28 / 1.8$ & 96 & 6 & - & 3.3 & 4. & 0.8 & 3. & 3.8 & 24 & 1109 & $3.6 \times 10^{15}$ & $3.9 \times 10^{-14}$ & $4.5 \times 10^{16}$ \\
\hline $\mathrm{N} 25$ & -1 & -1 & -1 & 1 & 11302 & 109 & 4.9 & 5 & 45 & 123 & - & - & - & 2. & 3.7 & 0.8 & 3 . & 3.9 & 24 & 941 & $2.7 \times 10^{13}$ & $1.4 \times 10^{-9}$ & $1.6 \times 10^{14}$ \\
\hline $\mathrm{N} 2$ & 1 & -1 & -1 & 1 & 1960 & 80 & 4.5 & 4 & 3 & 1. & - & - & - & 3. & - & - & 3 & 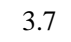 & 3 & 57 & - & - & - \\
\hline $\mathrm{N} 27^{b}$ & -1 & 1 & -1 & 1 & 11064 & 89 & - & - & - & - & - & - & - & 2.5 & 2.8 & 0.3 & 3. & 3.8 & 28 & 776 & $9.3 \times 10^{12}$ & $1.8 \times 10^{-9}$ & $3.8 \times 10^{14}$ \\
\hline $\mathrm{N} 28$ & 1 & 1 & -1 & 1 & 11344 & 112 & 4.4 & 0 & 19 & 224 & 281 & 26 & - & 5.7 & 6. & 0 & 1. & 10 & 81 & 158 & $5.6 \times 10^{14}$ & $3.4 \times 10^{-13}$ & $3.3 \times 10^{16}$ \\
\hline $\mathrm{N} 29$ & -1 & -1 & 1 & 1 & 1231 & 19 & 4.1 & 3 & $J$ & & 24 & 1 & 0.67 & 2.7 & 2. & & 3. & 3.1 & 33 & 862 & - & - & - \\
\hline N30 & 1 & -1 & 1 & 1 & 1667 & 56 & 4.7 & 4 & 33 & & - & - & - & 3.2 & 3. & 0 & 3. & 3.6 & 40 & 533 & $1.1 \times 10^{14}$ & $1.0 \times 10^{-11}$ & $5.7 \times 10^{15}$ \\
\hline N31 & -1 & 1 & 1 & 1 & 182 & 7 & 2.8 & 4 & 35 & 1.16 & - & - & - & 2.9 & 3.4 & 0.5 & 3.7 & 3.9 & 217 & 1719 & - & - & - \\
\hline N32 & 1 & 1 & 1 & 1 & 1120 & 10 & 3.5 & 4 & 29 & 1.51 & 155 & 12 & $<0.3$ & 3.6 & 3.8 & 0.2 & 3.0 & 3.1 & 404 & 616 & $4.8 \times 10^{15}$ & $6.3 \times 10^{-14}$ & $2.1 \times 10^{16}$ \\
\hline N33 & 0 & 0 & 0 & 0 & 0257 & 21 & 3.7 & 4 & 30 & 1.3 & - & - & - & 3.2 & 3.6 & 0.4 & 3.6 & 3.2 & 268 & 1177 & $2.4 \times 10^{14}$ & $2.3 \times 10^{-12}$ & $1.2 \times 10^{16}$ \\
\hline N34 & 0 & 0 & 0 & 0 & 0412 & 34 & 4.1 & 4 & 32 & 1.45 & - & - & - & 3.1 & 3.6 & 0.5 & 3.6 & 3.7 & 28 & 1073 & $3.4 \times 10^{12}$ & - & - \\
\hline N35 & 0 & 0 & 0 & 0 & 0357 & 30 & 4.6 & 2 & 41 & 1.30 & - & - & - & 3.1 & 3 & 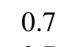 & 3 & & 21 & 1261 & $2.8 \times 10^{12}$ & $2.4 \times 10^{-10}$ & $9.5 \times 10^{15}$ \\
\hline N36 & 0 & 0 & 0 & 0 & 0325 & 27 & 3.9 & 4 & 3 & 1.26 & - & - & - & 3.1 & 3.8 & 0.7 & 3.7 & 3.8 & 198 & 1381 & - & - & - \\
\hline N37 & 0 & 0 & 0 & 0 & 0272 & 23 & 4.1 & 4 & 32 & & - & - & 0.68 & 3.1 & 3.7 & & 3.6 & 3.7 & 228 & 1255 & $6.6 \times 10^{13}$ & $2.6 \times 10^{-12}$ & $3.7 \times 10^{16}$ \\
\hline$\sigma$ & & & & & 63 & 5 & 0.3 & 0.9 & 4 & 0.08 & - & - & - & 0.04 & 0.1 & 0.1 & 0.04 & 0.2 & 37 & 114 & $1.0^{c}$ & $1.1^{c}$ & $0.3^{c}$ \\
\hline
\end{tabular}

${ }^{a}$ Film is too thin to analyze by all techniques. ${ }^{b}$ Film delaminated prior to analysis by all techniques. ${ }^{c}$ Reported as the standard deviation of the logarithmic values. 


\section{RESULTS AND DISCUSSION}

\subsection{Full Factorial Experiment Analysis}

Results from the full factorial DOE (Table 2) were analyzed to ascertain significant effects. Main effects and interaction effects, as well as their standard errors, $t$-ratios and $P$-values [59], were calculated using SAS software [65] and are summarized in Table S1 (Supplementary Information). Standard deviation values $(\sigma)$ were independently calculated from the center point runs, and are additionally included in Table 2. Main effects are defined as the effect of each individual factor (i.e, each individual PECVD process parameter) on a given response (i.e., property). The effect of factor A, for example can be represented by the difference between the average response value at all high levels of $\mathrm{A}\left(\mathrm{A}_{+}\right)$and the average response at all low levels of A (A_):

$$
\operatorname{Effect}\left(\mathrm{A}_{)}=\operatorname{Avg}\left(\mathrm{A}_{+}\right)-\operatorname{Avg}\left(\mathrm{A}_{-}\right)\right.
$$

Interaction effects occur when the effect of one factor depends on another. The interaction effect between factors $\mathrm{A}$ and $\mathrm{B}$, for example, can be represented as one half of the difference between the effect of $\mathrm{A}$ at the high level of B and the effect of A at the low level of B:

$$
\operatorname{Effect}(\mathrm{AB})=1 / 2\left\{\left[\operatorname{Avg}\left(\mathrm{A}_{+}\right)-\operatorname{Avg}\left(\mathrm{A}_{-}\right)\right]_{\mathrm{B}_{+}}-\left[\operatorname{Avg}\left(\mathrm{A}_{+}\right)-\operatorname{Avg}\left(\mathrm{A}_{-}\right)\right]_{\mathrm{B}_{-}}\right\}
$$

The statistical significance of each effect was evaluated from the $t$-ratio and $P$-value, where the $t$-ratio is given as the magnitude of the effect divided by its standard error, and $P$-values $<0.05$ indicate significance at the $95 \%$ confidence level.

To aid in evaluating correlations between responses (properties), the Pearson and Spearman rankorder correlation coefficients ( $r$ and $r_{\mathrm{S}}$, respectively) [66] were compiled and are summarized in Tables 3 and S2, respectively. The Pearson correlation coefficient is a measure of the strength and direction of the association between two variables that are linearly correlated. From an examination of scatter plots, the majority of the sets of variables that exhibit correlation appear to be linearly correlated, and therefore the Pearson correlation coefficient is expected to do an adequate job of estimating correlation strength. In a few cases, however, the variables are correlated in a clearly non-linear fashion or the data exhibits heteroscedasticity (changing variance along the line of best fit) or contains distinct outliers. In such cases the Spearman correlation coefficient may do a better job of estimating correlation strength. From a comparison of $r$ and $r_{\mathrm{S}}$ values, we observe that the two are generally very close, and conclude that either 

define a strong correlation as one with $r / r_{\mathrm{S}}>0.6$, a moderate correlation as one with $0.3<r / r_{\mathrm{S}}<0.6$, and a weak correlation as one with $r / r_{\mathrm{S}}<0.3$.

Table 3. Pearson correlation coefficients, $r$, for a-B ${ }_{x} \mathrm{C}: \mathrm{H}_{y}$ properties. All values of $r>0.6$ are highlighted in bold.

\begin{tabular}{|c|c|c|c|c|c|c|c|c|c|c|c|c|c|c|c|c|c|}
\hline & Gr. rate & $\mathrm{B} / \mathrm{C}$ & At. $\%$ O & At. $\% \mathrm{H}$ & Density & $E$ & $\boldsymbol{H}$ & $\varepsilon_{1}$ & $\boldsymbol{\kappa}$ & $\kappa-\varepsilon_{1}$ & $E_{\text {Tauc }}$ & $E_{04}$ & $E_{\mathbf{U}}$ & $B^{1 / 2}$ & $\log \rho$ & $\log \mu_{\mathrm{F}}$ & $\log n$ \\
\hline Gr. rate & & 0.74 & -0.27 & 0.00 & 0.18 & 0.49 & 0.56 & 0.35 & 0.48 & 0.12 & -0.32 & -0.34 & 0.43 & -0.58 & 0.03 & 0.44 & -0.60 \\
\hline $\mathrm{B} / \mathrm{C}$ & 0.74 & & -0.49 & 0.03 & 1 & 0.26 & 0.28 & 0.27 & 0.24 & -0.14 & 27 & -0.32 & 0.40 & -0.68 & 0.00 & 0.54 & -0.60 \\
\hline At. $\%$ O & -0.27 & -0.49 & & 0.40 & -0.35 & -0.81 & -0.78 & -0.61 & -0.52 & 0.36 & 0.64 & 0.59 & -0.67 & 0.66 & -0.29 & 0.20 & -0.09 \\
\hline At. \% H & 0.00 & 0.03 & 0.40 & & -0.84 & -0.97 & -0.95 & -0.83 & -0.68 & 0.56 & 0.69 & 0.69 & -0.67 & 0.50 & -0.44 & 0.67 & -0.55 \\
\hline Density & 0.18 & 0.11 & -0.35 & -0.84 & & 0.92 & 0.96 & 0.85 & 0.76 & -0.47 & -0.68 & -0.66 & 0.62 & -0.48 & 0.38 & -0.62 & 0.64 \\
\hline$E$ & 0.49 & 0.26 & -0.81 & -0.97 & 0.92 & & 0.99 & 0.97 & 0.88 & -0.54 & -0.90 & -0.85 & 0.89 & -0.86 & 0.37 & -0.56 & 0.41 \\
\hline $\boldsymbol{H}$ & 0.56 & 0.28 & -0.78 & -0.95 & 0.96 & 0.99 & & 0.97 & 0.92 & -0.48 & -0.90 & -0.86 & 0.90 & -0.84 & 0.34 & -0.54 & 0.44 \\
\hline$\varepsilon_{1}$ & 0.35 & 0.27 & -0.61 & -0.83 & 0.85 & 0.97 & 0.97 & & 0.91 & -0.49 & -0.87 & -0.86 & 0.88 & -0.75 & 0.37 & -0.37 & 0.19 \\
\hline $\boldsymbol{\kappa}$ & 0.48 & 0.24 & -0.52 & -0.68 & 0.76 & 0.88 & 0.92 & 0.91 & & -0.09 & -0.79 & -0.75 & 0.79 & -0.67 & 0.31 & -0.29 & 0.19 \\
\hline$\kappa-\varepsilon_{1}$ & 0.12 & -0.14 & 0.36 & 0.56 & -0.47 & -0.54 & -0.48 & -0.49 & -0.09 & & 0.45 & 0.50 & -0.46 & 0.42 & -0.19 & 0.33 & -0.31 \\
\hline $\boldsymbol{E}_{\text {Tauc }}$ & -0.32 & -0.27 & 0.64 & 0.69 & -0.68 & -0.90 & -0.90 & -0.87 & -0.79 & 0.45 & & 0.87 & -0.96 & 0.72 & -0.40 & 0.33 & -0.14 \\
\hline$E_{04}$ & -0.34 & -0.32 & 0.59 & 0.69 & -0.66 & -0.85 & -0.86 & -0.86 & -0.75 & 0.50 & 0.87 & & -0.89 & 0.70 & -0.38 & 0.25 & -0.08 \\
\hline $\boldsymbol{E}_{\mathbf{U}}$ & 0.43 & 0.40 & -0.67 & -0.67 & 0.62 & 0.89 & 0.90 & 0.88 & 0.79 & -0.46 & -0.96 & -0.89 & & -0.82 & 0.34 & -0.24 & 0.02 \\
\hline$B^{1 / 2}$ & -0.58 & -0.68 & 0.66 & 0.50 & -0.48 & -0.86 & -0.84 & -0.75 & -0.67 & 0.42 & 0.72 & 0.70 & -0.82 & & -0.37 & 0.12 & 0.22 \\
\hline$\rho$ & 0.03 & 0.00 & -0.29 & -0.44 & 0.38 & 0.37 & 0.34 & 0.37 & 0.31 & -0.19 & -0.40 & -0.38 & 0.34 & -0.37 & & -0.82 & 0.29 \\
\hline$\mu_{\mathrm{F}}$ & 0.44 & 0.54 & 0.20 & 0.67 & -0.62 & -0.56 & -0.54 & -0.37 & -0.29 & 0.33 & 0.33 & 0.25 & -0.24 & 0.12 & -0.82 & & -0.77 \\
\hline$n$ & -0.60 & -0.60 & -0.09 & -0.55 & 0.64 & 0.41 & 0.44 & 0.19 & 0.19 & -0.31 & -0.14 & -0.08 & 0.02 & 0.22 & 0.29 & -0.77 & \\
\hline
\end{tabular}

Although the process parameter effects can be evaluated quantitatively from Table S1 alone, a graphical analysis is very useful. We have produced Pareto charts and interaction effect plots for a majority of the responses. Pareto charts are simple bar graphs that allow for a quick assessment of relative magnitude and statistical significance of the different effects (colored bars represent statistically significant effects). Interaction plots provide a visual means for understanding the interactions between factors: most simply, the more the lines deviate from parallel, the greater the interaction.

\subsection{Growth Rate}

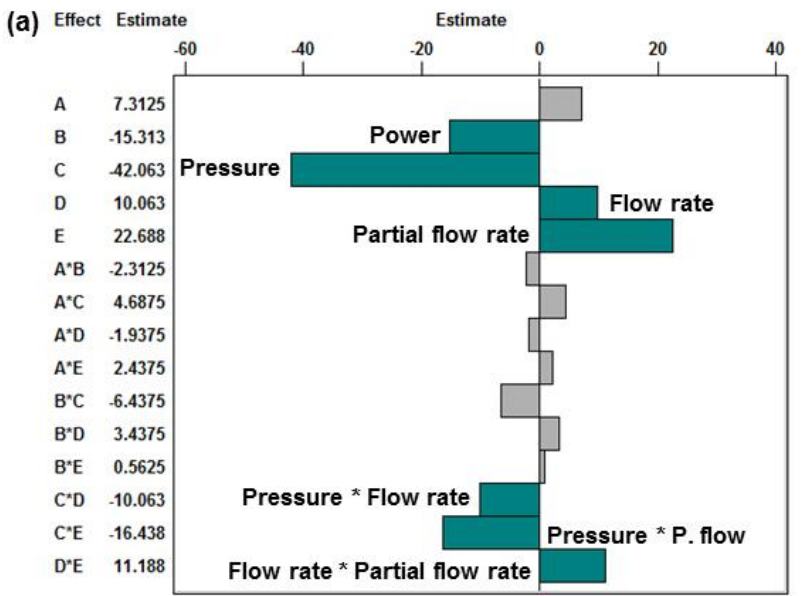

(b)

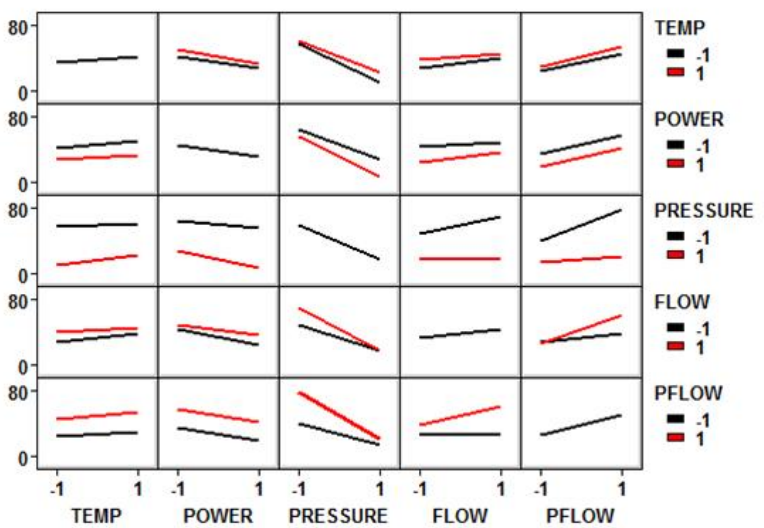

Figure 1. Pareto chart (a) and interaction effects (b) for growth rate. 
From Figure 1, it is evident that pressure and partial flow rate have the greatest effect on growth rate. High pressure conditions decrease growth rate, while high partial flow rate conditions increase it. The interaction between these two variables is also relatively significant, and we can observe in the interaction effect plot that the influence of pressure is greater at high partial flow rates. Power and total flow rate also demonstrate statistically significant effects, although their magnitude is smaller. An increase in growth rate with increasing partial pressure of precursor would be expected based on the higher delivery rate of reactive species to the substrate surface. A decrease in growth rate with increasing pressure can also be explained by the smaller mean free path of reactive species and thus lower delivery rate to the substrate surface. The fact that temperature does not show a significant effect on growth rate suggests that growth rate is primarily limited by mass transport rather than reaction rate, which is consistent with a (relatively) low temperature plasma-assisted CVD process. Further, the fact that increasing power is correlated with a decrease in growth rate may suggest that film growth is not accelerated by increased ion bombardment by higher energy ions, as one might expect [62,67]. However, these interpretations are convoluted by the effects of temperature and power on thin-film density (vide infra); although higher temperature and power conditions may not correlate with a high growth rate calculated via film thickness/growth time, they would be expected to show a stronger influence on growth rate if this were interpreted in terms of total mass density (i.e., thin-film density $\times$ thickness). Overall, the results indicate that to optimize for growth rate in a- $\mathrm{B}_{x} \mathrm{C}: \mathrm{H}_{y}$, we would want to apply conditions of low power, low pressure, high flow rate, and high partial flow rate. 


\subsection{Chemical Composition and Mechanical Properties}

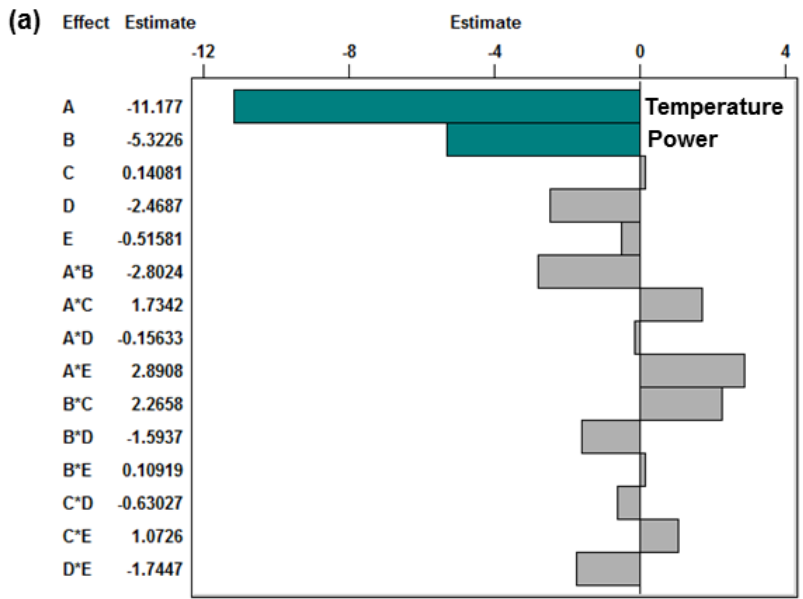

(c) Effect Estimate

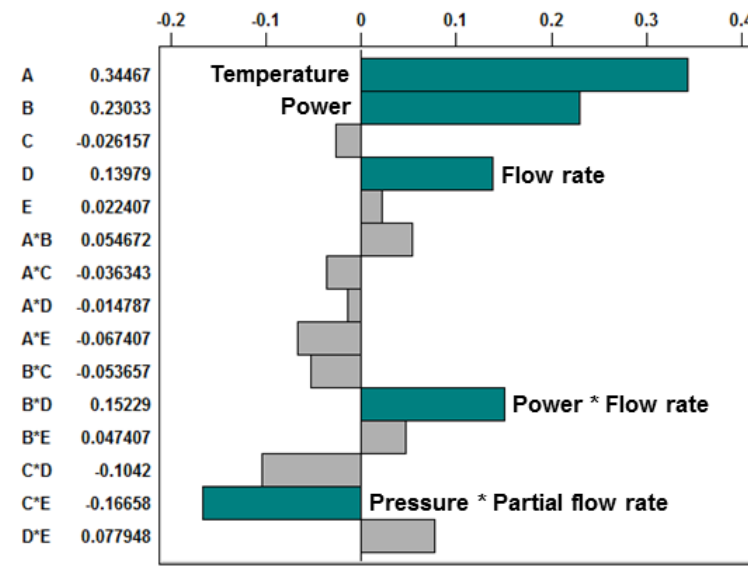

(b)

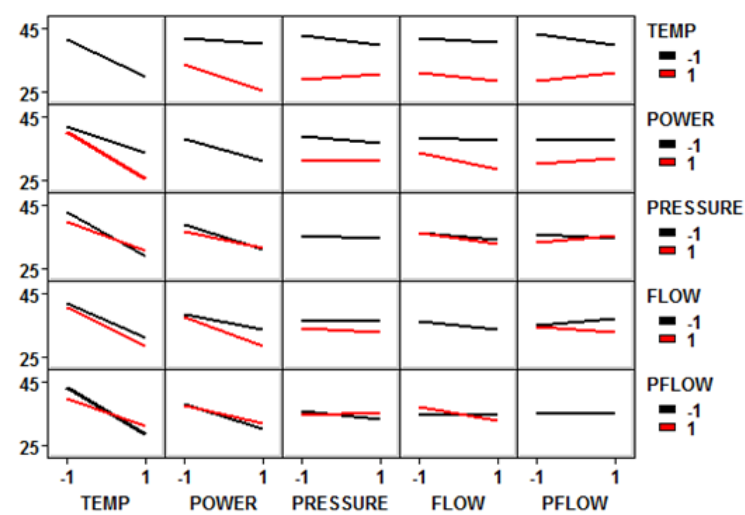

(d)

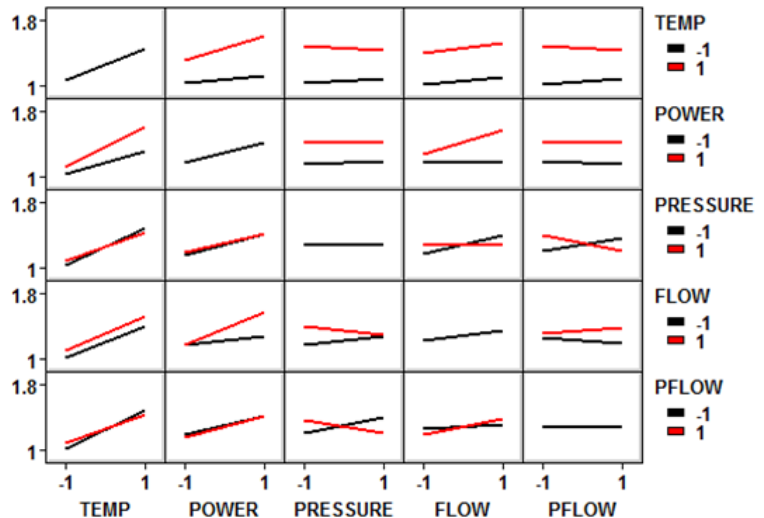

Figure 2. Pareto charts and interaction effects for atomic concentration hydrogen [(a) and (b)] and density $[(\mathrm{c})$ and $(\mathrm{d})]$. 
(a)

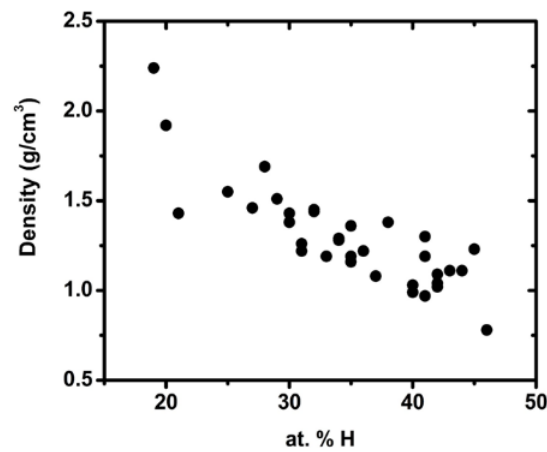

(c)

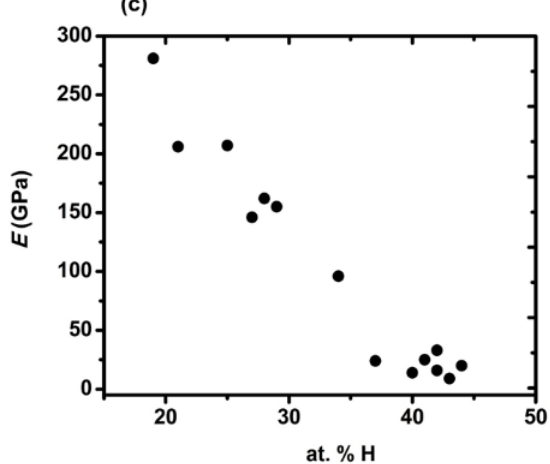

(b)

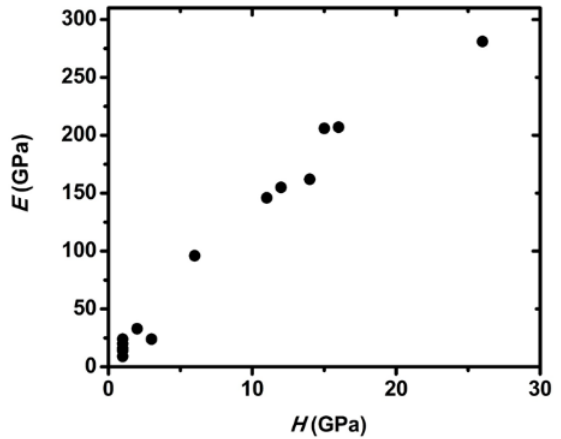

(d)

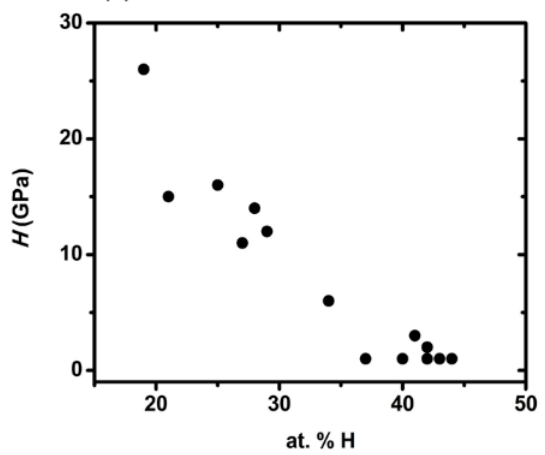

Figure 3. (a) Density as a function of atomic concentration hydrogen (at.\% H), (b) Young's modulus $(E)$ as a function of hardness $(H),(c) E$ as a function of at. $\% \mathrm{H}$, and (d) $H$ as a function of at. $\% \mathrm{H}$.

(a) Effect Estimate

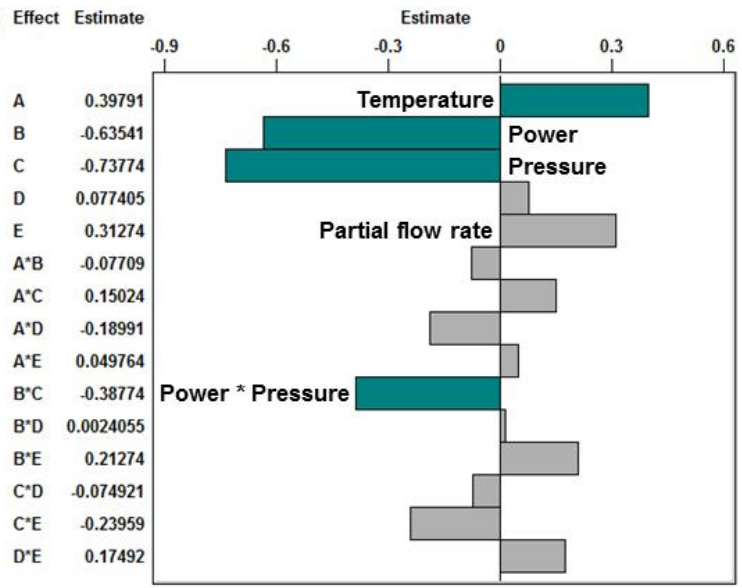

(b)

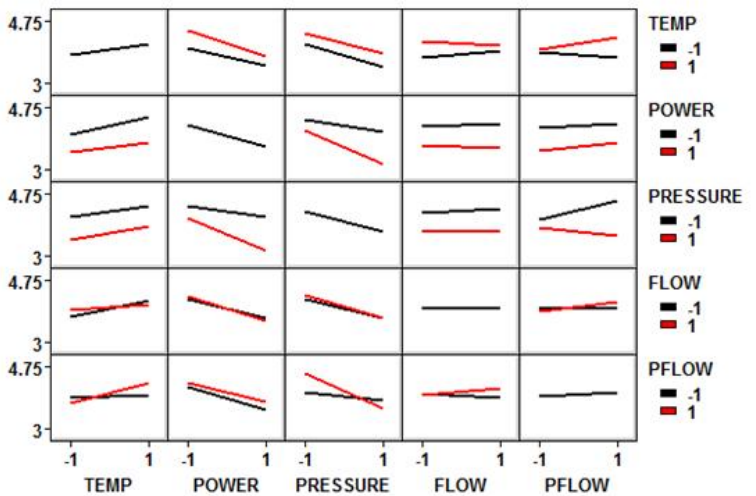

Figure 4. Pareto chart (a) and interaction effects (b) for boron-to-carbon ratio. 

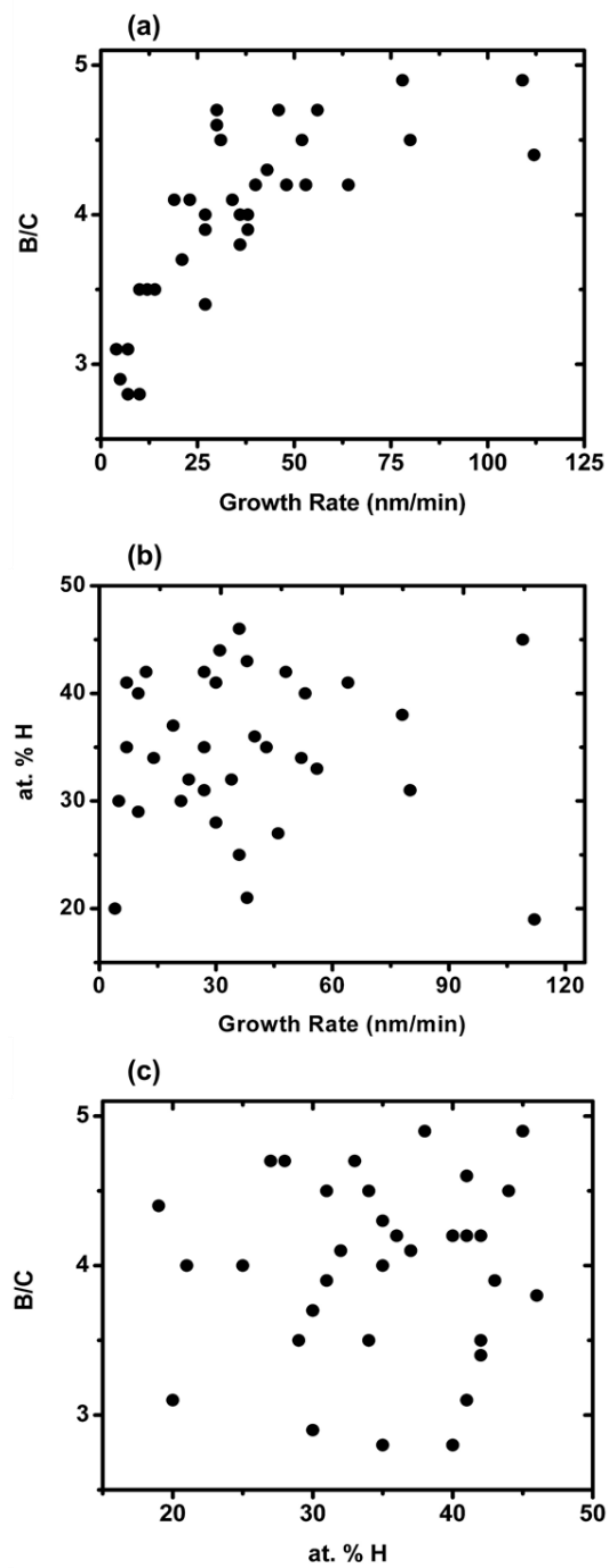

Figure 5. (a) Boron-to-carbon ratio and (b) atomic concentration hydrogen as a function of growth rate, as well as (c) boron-to-carbon ration as a function of at. $\% \mathrm{H}$ displaying a lack of correlation.

In the case of atomic concentration hydrogen (at.\% $\mathrm{H}$ ), only growth temperature and power are observed to be significant effects, where increasing either parameter leads to a decrease in hydrogen content, with the effect of temperature being about twice that of power [Figures 2(a) and (b)]. Similar dominant temperature and power effects are observed for density, but of opposite sign, where increasing either parameter leads to an increase in density. These observations are consistent with our previous investigation of $\mathrm{a}-\mathrm{B}_{x} \mathrm{C}: \mathrm{H}_{y}$ films grown while varying temperature and power only [58]. In agreement with this earlier work, hydrogen content and density show a strong inverse correlation, as evident from the 

temperature and power on hydrogen content and density are not surprising. Increasing temperature presumably allows access to thermodynamically favorable reactions involving $\mathrm{H}$ removal and/or crosslinking, while the greater ion energy and ion bombardment from increasing power can facilitate $\mathrm{H}$ removal, formation of reactive sites, and overall densification. It is noteworthy that pressure or the power*pressure interaction do not show up as statistically significant effects, like they do for many other properties (vide infra).

Young's modulus and hardness were investigated through nanoindentation experiments. Because only a subset of samples was selected for these measurements, there is not enough data for $E$ and $H$ to perform a full statistical analysis. We note, however, that these two properties display a direct linear correlation with each other $[r=0.99$; Figure 3(b)] and, consistent with previous work [58], correlate linearly with hydrogen content/density [with $r$ values of -0.97 and -0.95 for $E$ and $H$ vs at.\% $\mathrm{H}$, respectively), while demonstrating what has been assigned to a rigidity percolation threshold at $\sim 35 \% \mathrm{H}$ [Figures 3(c) and (d)]. Thus, we can assume that these mechanical properties can be mapped directly by either at.\% $\mathrm{H}$ or density and would depend similarly on growth conditions (i.e., primarily temperature and power). We have also determined pore size in a selection of films using positron annihilation lifetime spectroscopy (PALS). In six low-density films $\left(0.8-1.1 \mathrm{~g} / \mathrm{cm}^{3}\right)$, pore diameters of $0.67-0.73 \mathrm{~nm}$ were measured. In one high-density film $\left(\mathrm{N} 16,1.9 \mathrm{~g} / \mathrm{cm}^{3}, 20 \% \mathrm{H}\right)$ measured, no pores could be detected, indicating that any pores in this film are below the PALS lower detection limit of $\sim 0.3 \mathrm{~nm}$. The results for the three moderate-density films studied are mixed: for film N37, with a density of $1.44 \mathrm{~g} / \mathrm{cm}^{3}(32 \% \mathrm{H})$, a pore diameter of 0.68 was measured, whereas for films $\mathrm{N} 32\left(1.51 \mathrm{~g} / \mathrm{cm}^{3}, 29 \% \mathrm{H}\right)$ and $\mathrm{N} 4\left(1.43 \mathrm{~g} / \mathrm{cm}^{3}, 21 \% \mathrm{H}\right)$, no pores could be detected. The density measured for N4 is likely anomalously low [it appears as a clear outlier in the at. $\% \mathrm{H}$ vs density plot in Figure 3(a)], and this film should probably be considered in the higher density range. In the case of $\mathrm{N} 32$ and N37, it is possible that these lie very near the percolation threshold, which may explain the detection of pores in one case but not the other. Overall, the general correlation between pore diameter and density suggests that porosity is also predominantly controlled by growth temperature and power.

The effect of process parameters on the $\mathrm{B} / \mathrm{C}$ ratio are very different than those on atomic concentration hydrogen. Temperature, power, pressure, and the power*pressure interaction are all significant effects (Figure 4). In particular, increasing power and increasing pressure are both correlated with a lower $\mathrm{B} / \mathrm{C}$ ratio, and thus increased carbon content. The interaction between the two is such that the effect of pressure is greater at high power, and vice versa. There is also a noteworthy overlap between the effect profiles for $\mathrm{B} / \mathrm{C}$ ratio and growth rate: although not all the same effects register as statistically significant in both cases, their signs and relative magnitudes follow the same trend. This observation 
prompted us to look more closely at the correlation between these two responses. Indeed, the $\mathrm{B} / \mathrm{C}$ ratio does show a strong correlation with growth rate $[r=0.74$, Figure 5(a) $]$, whereas at.\% $\mathrm{H}$ does not $[r=$ 0.00 , Figure $5(\mathrm{~b})]$. Further, the $\mathrm{B} / \mathrm{C}$ ratio and the at. $\% \mathrm{H}$ are not at all correlated with each other $[r=0.03$, Figure 5(c)]. Since the correlation between B/C ratio and growth rate is clearly non-linear (although it may be considered linear below a plateau of $\sim 4.5-5$ ), this is an example where the Spearman ranked correlation coefficient may be more appropriate, and in this case, it indicates a slightly stronger correlation than the Pearson coefficient $\left(r_{\mathrm{S}}=0.81\right)$. One explanation for the correlation between growth rate and carbon content can be traced back to the plasma chemistry associated with low growth rates. At higher pressure and power growth conditions, a higher frequency of collisions with higher energy ions would be expected, which could conceivably lead to a greater number of dissociated carborane molecules and free carbon-based reactive species reaching the substrate surface and incorporating into the thin film. 
(a) Effect Estimate

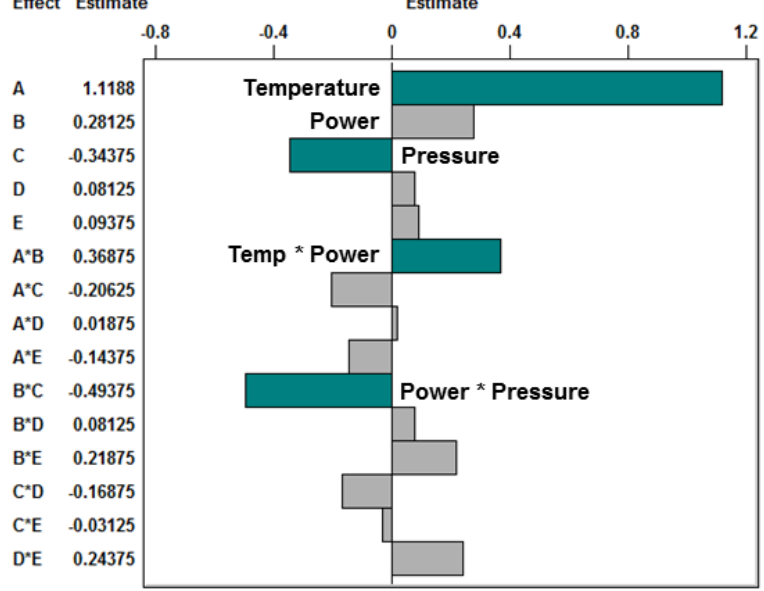

(c) Effect Estimate

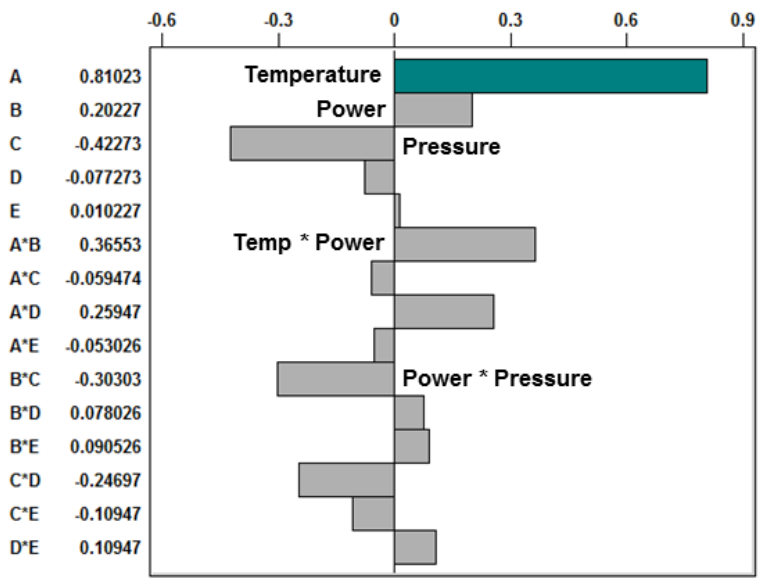

(e) Effect Estimate

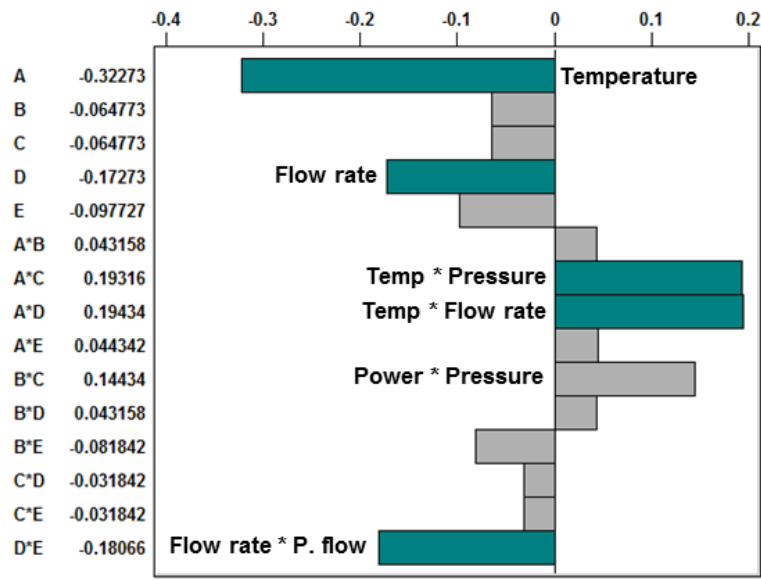

(b)

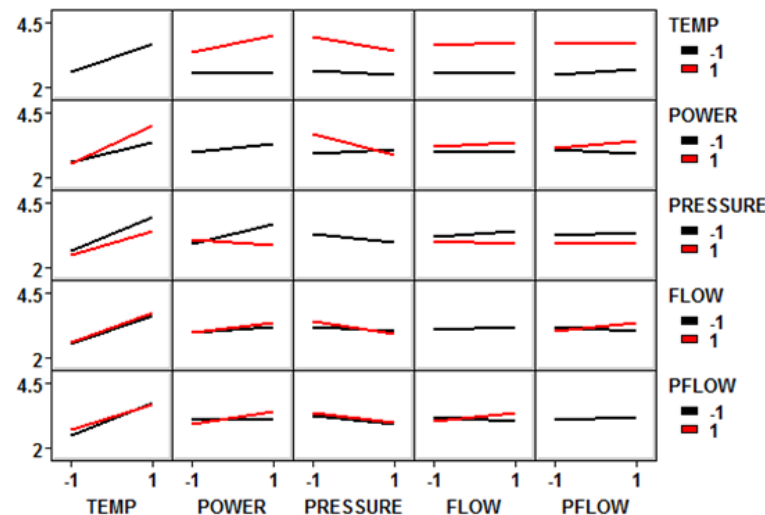

(d)

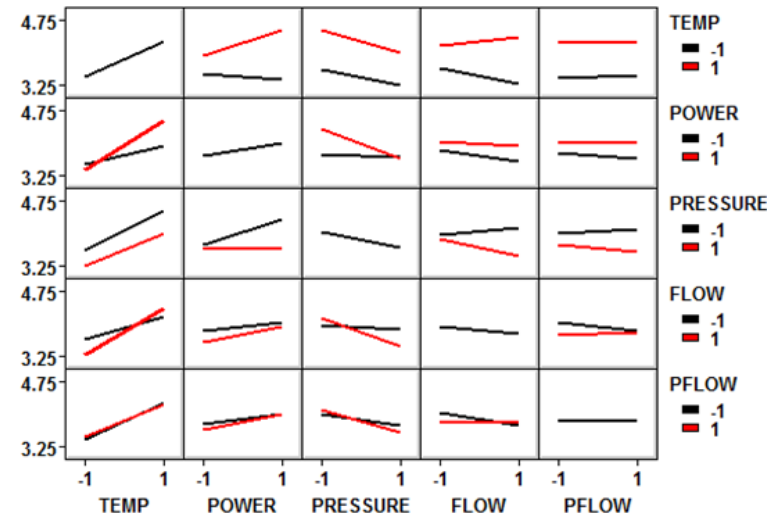

(f)

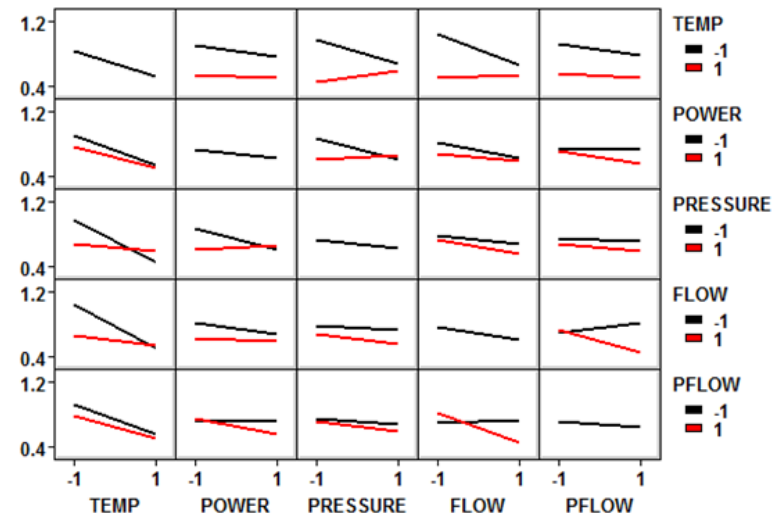

Figure 6. Pareto chart and interaction effects for high-frequency dielectric constant $\left(\varepsilon_{1}\right)[(a)$ and (b)], total dielectric constant $(\kappa)[(\mathrm{c})$ and $(\mathrm{d})]$, and the difference between the two $\left(\kappa-\varepsilon_{1}\right)$ [(e) and (f)]. 
(a)

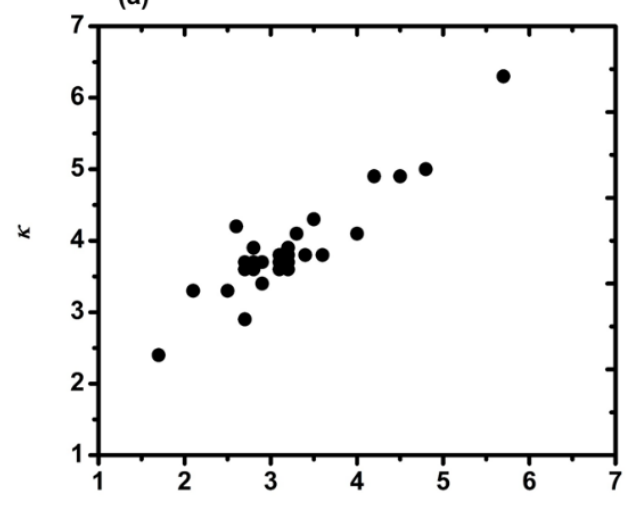

(b)

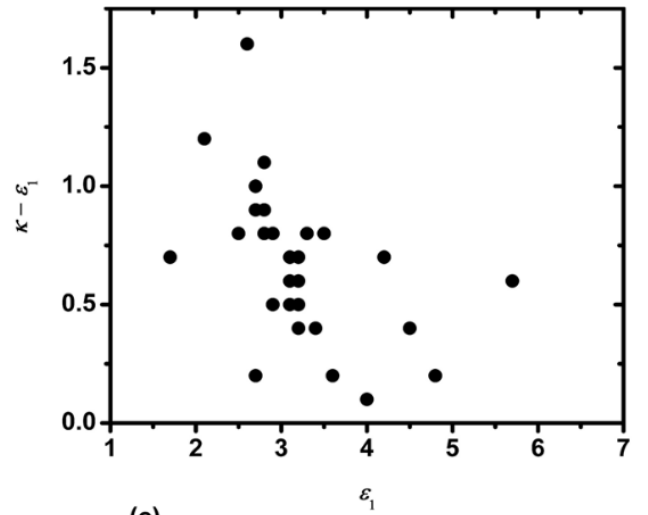

(c)

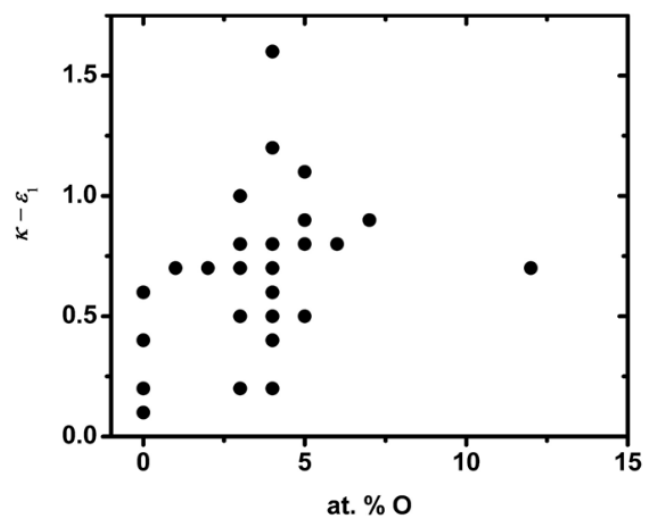

Figure 7. Correlations between different components of the dielectric constant: (a) $\kappa$ vs $\varepsilon_{1}$, (b) $\kappa-\varepsilon_{1}$ vs $\varepsilon_{1}$, and (c) $\kappa-\varepsilon_{1}$ vs atomic concentration oxygen.

\subsection{Dielectric Properties}

The high-frequency $\left(\varepsilon_{1}\right)$, low-frequency (total, $\left.\kappa\right)$, and intermediate-frequency $\left(\kappa-\varepsilon_{1}\right)$ dielectric constant speak to the electronic, orientation, and distortion contributions to the total polarization response of a material [68]. Where the high-frequency dielectric constant is concerned, growth temperature has by far the greatest effect, where increasing from a low to a high temperature increases $\varepsilon_{1}$ by $\sim 1$ [Figure 6(a)]. The second greatest effect is the power*pressure interaction. The large interaction between power and 
pressure implies that each of these variables does in fact have a significant effect, but that the sign of this effect depends on the level of the interacting factor. Thus, at low pressure, increasing power increases $\varepsilon_{1}$, while at high pressure, increasing power decreases $\varepsilon_{1}$-a result that is not evident from the main effects alone. A similar argument can be made for the effects of pressure as a function of power level. From this information, we can identify two opposite regimes that would lead to a low $\varepsilon_{1}$ : low power and low pressure or high power and high pressure. These results are consistent with our previous study investigating the effects of temperature and power only, where increasing power led to an increase in $\varepsilon_{1}$ while holding the pressure constant at a "low" value of 0.2 Torr [58]. The interaction between power and pressure is expected since both conditions together play a role in determining overall ion energy, where increasing power or decreasing pressure can lead to higher energy ions. Thus, a combination of either high power and high pressure or low power and low pressure would conceivably lead to comparably moderate ion energies (in contrast to high power and low pressure or low power and high pressure combinations, expected to yield high or low energy ions respectively).

Temperature also has a large, statistically significant effect in the response of $\kappa$ [Figure $6(\mathrm{~b})]$. No other effects are statistically significant, but their magnitudes generally follow the same trends as in the case of $\varepsilon_{1}$; thus, similar power and pressure effects and interactions are expected. As evident from Figure $7(\mathrm{a}), \kappa$ correlates quite closely with $\varepsilon_{1}(r=0.91)$; however, from Figure 7(b), we see that the difference between the two $\left(\kappa-\varepsilon_{1}\right)$ is higher at lower $\varepsilon_{1}$ values. In previous work, we hypothesized that this increase in $\kappa-\varepsilon_{1}$ was correlated with increased oxygen content, leading to a higher concentration of polar bonds [58]. It is possible that this is the case here: $\kappa-\varepsilon_{1}$ and atomic concentration oxygen are correlated [Fig 7(c)], but weakly $(r=0.36)$, and in fact the correlation between $\kappa-\varepsilon_{1}$ and at.\% $\mathrm{H}$ is stronger $(r=0.56)$. This suggests that there may be an additional chemical/physical mechanism underlying this result. The most significant effect on $\kappa-\varepsilon_{1}$ is temperature, but its magnitude is of the opposite sign as in the case of $\varepsilon_{1}$ or $\kappa$. Several other main and interaction effects are also of statistical significance, including temperature*pressure and temperature*flow rate interactions, which suggests that even at low temperature, it may be possible to minimize $\kappa-\varepsilon_{1}$ if higher pressures and flow rates are used. 


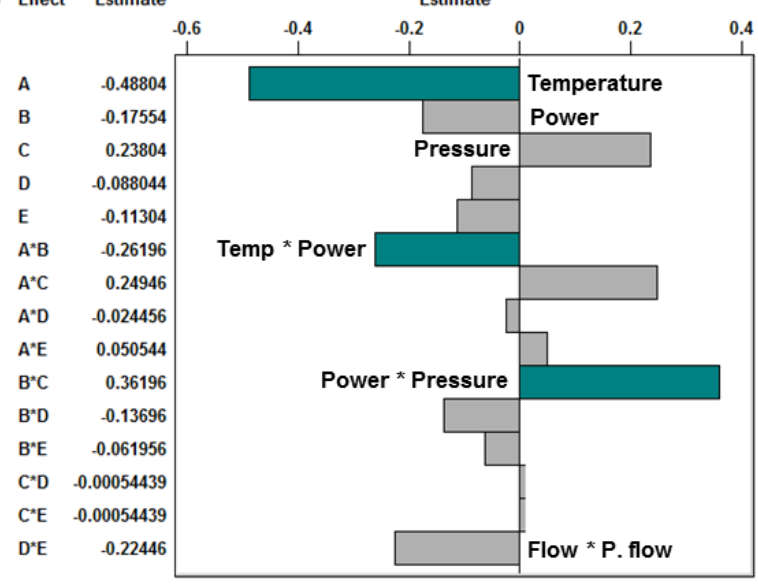

(c) Effect Estimate
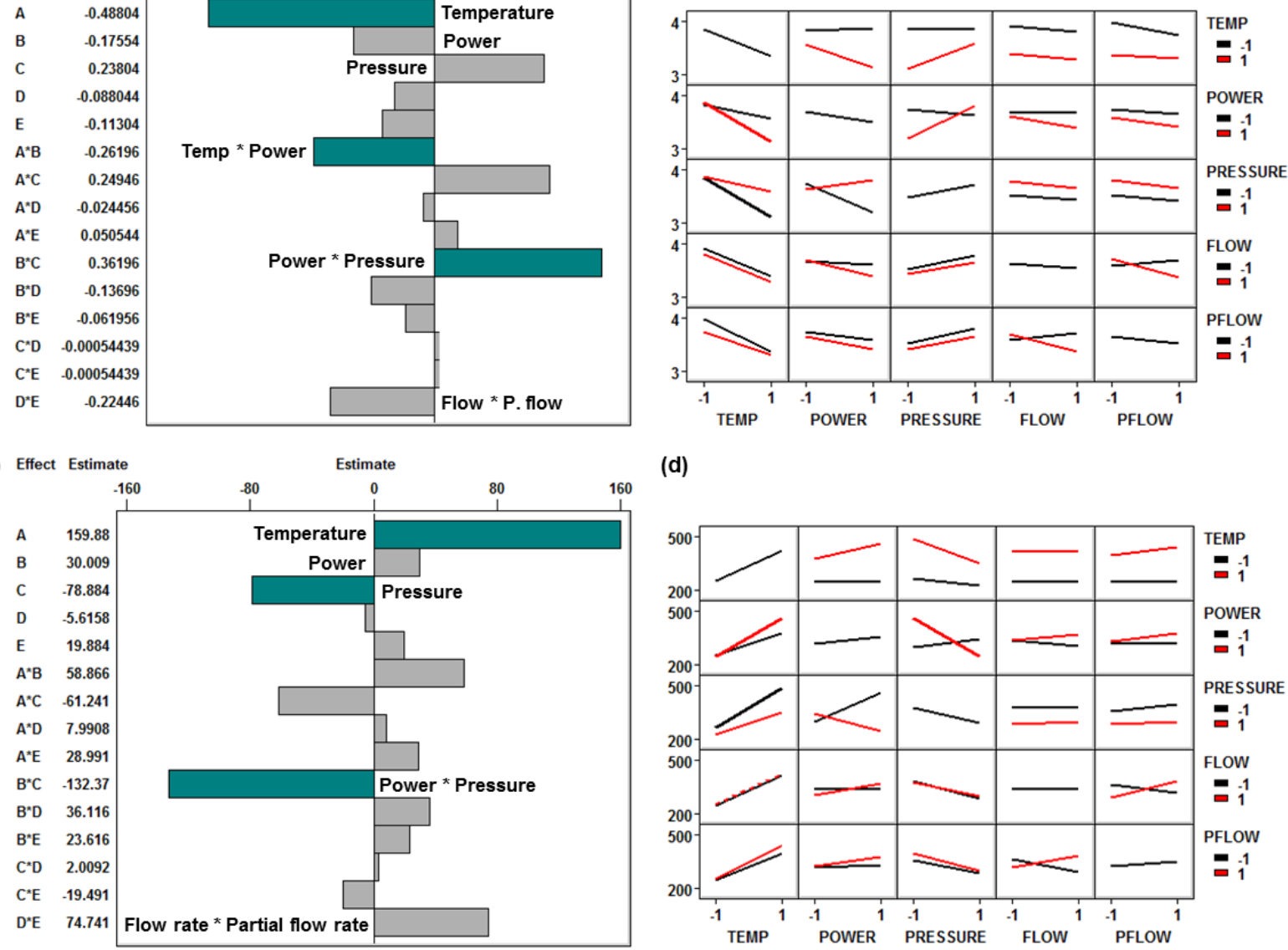

(d)

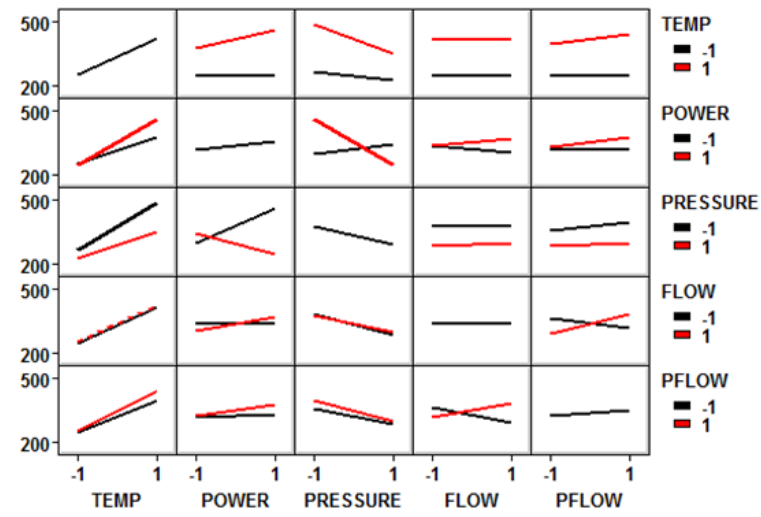

(e) Effect Estimate

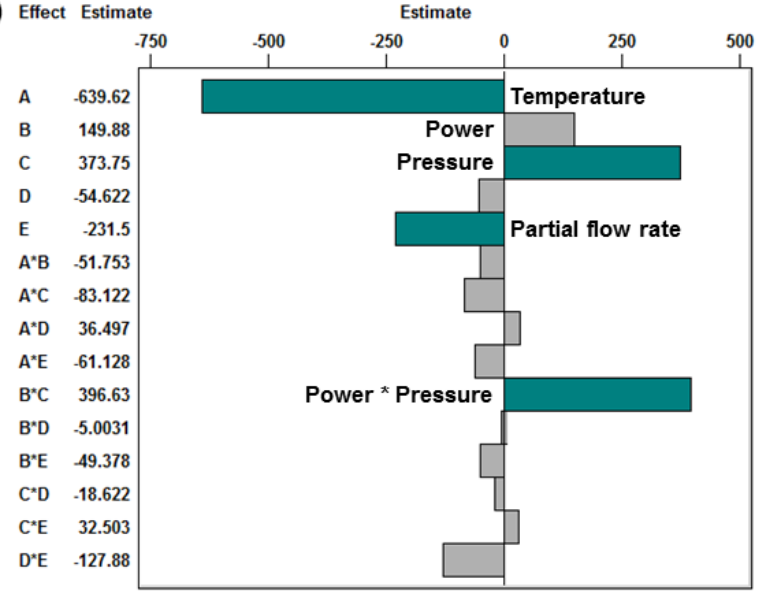

(f)

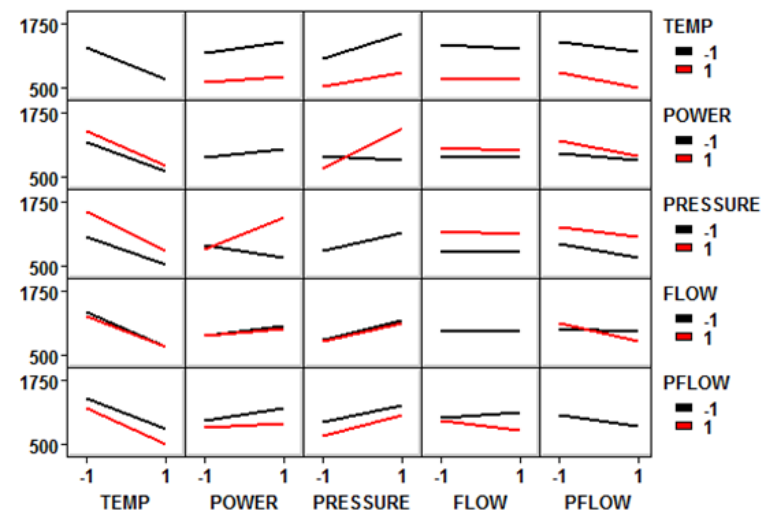

Figure 8. Pareto chart and interaction effects for optical band gap $\left(E_{04}\right)\left[(a)\right.$ and (b)], Urbach energy $\left(E_{\mathrm{U}}\right)$ $[(\mathrm{c})$ and $(\mathrm{d})]$, and Tauc parameter $\left(B^{1 / 2}\right)[(\mathrm{e})$ and $(\mathrm{f})]$. 

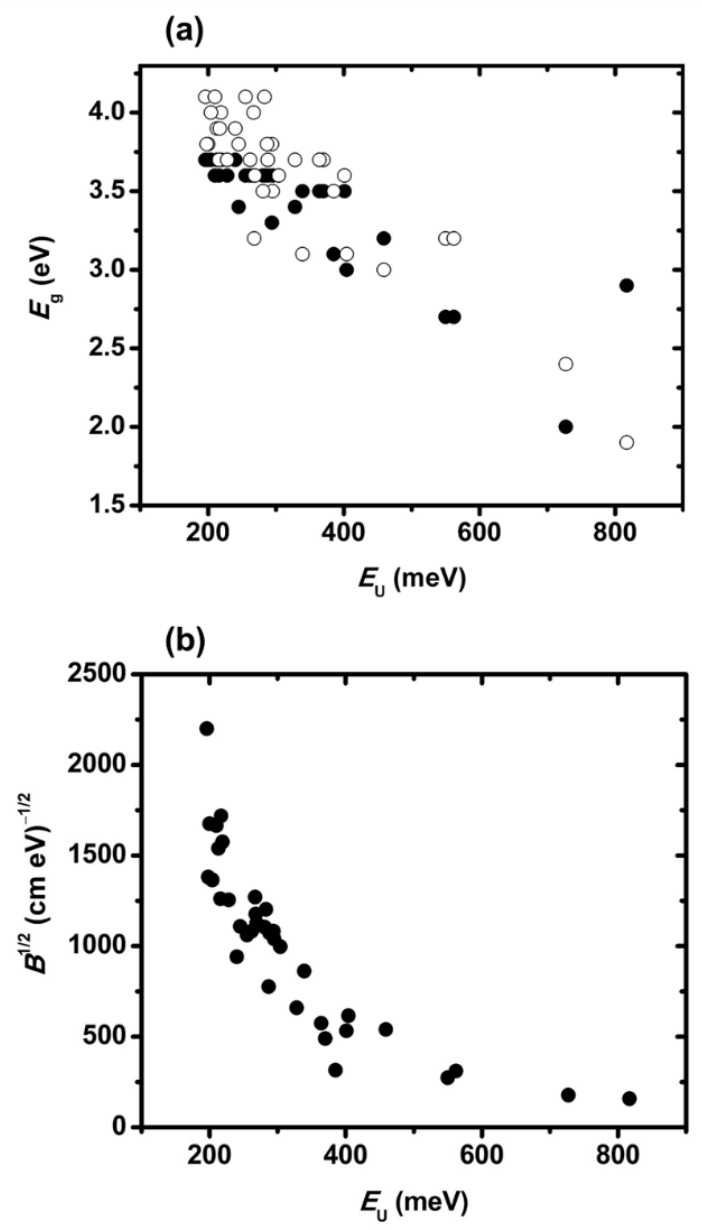

Figure 9. Correlations between (a) Tauc optical band gap $\left(E_{\text {Tauc }}, \bullet\right)$ and isoabsorption gap $\left(E_{04}, \circ\right)$ with Urbach energy $\left(E_{\mathrm{U}}\right)$, and (b) Tauc parameter $\left(\mathrm{B}^{1 / 2}\right)$ with $E_{\mathrm{U}}$.

\subsection{Electronic Structure}

Next, we look at electronic structure parameters obtained from optical transmission spectroscopy measurements including optical band gap $\left(E_{\mathrm{g}}\right)$ as well as Urbach energy $\left(E_{\mathrm{U}}\right)$ and Tauc parameter $\left(B^{1 / 2}\right)$, two measures of disorder in amorphous materials [58,69-71]. To determine band gap, we have calculated both the Tauc band gap, $E_{\text {Tauc }}$, and the isoabsorption gap, $E_{04}$. The average difference between the two is very small, $\sim 0.1 \mathrm{eV}$, and we therefore conclude that they can interchangeably provide a useful measure of optical gap in a- $\mathrm{B}_{x} \mathrm{C}: \mathrm{H}_{y}$. For this particular set of films, the band gap tends to be high $(>3.5 \mathrm{eV})$ in a majority of the samples. The $E_{\text {Tauc }}$ data appears to plateau at 3.6-3.7 eV, which may be an artifact of the analysis procedure: because the transmission cutoff for the glass substrates used is $\sim 4 \mathrm{eV}$, the fit to the Tauc edge may not be as accurate in the case of the high band gap samples. Indeed, the $E_{04}$ data does not show this same plateau, and appears to better represent the data for samples with $E_{\mathrm{g}}>3.5 \mathrm{eV}$ [see, for 
example, the $E_{\mathrm{g}}$ vs $E_{\mathrm{U}}$ correlation plot in Figure 9(a)]. In terms of the effects of the process parameters on $E_{\mathrm{g}}, E_{\mathrm{U}}$, and $B^{1 / 2}$, the most significant is growth temperature, and the second most significant is the power*pressure interaction, similarly to the case of the dielectric properties. Once more, two growth regimes are identified: high pressure and high power, or low pressure and low power. Another interaction effect that may be relevant because it points to the existence of opposite growth regimes is the flow rate*partial flow rate interaction. Although not statistically significant, the same trends in this interaction effect are observed for $\varepsilon_{1}, \kappa, \kappa-\varepsilon_{1}, E_{\mathrm{g}}, E_{\mathrm{U}}$, and $B^{1 / 2}$, which suggests that the effect should be taken into account when evaluating the influence of process conditions. As we have found before for $\mathrm{a}-\mathrm{B}_{x} \mathrm{C}: \mathrm{H}_{y}[58]$. band gap is observed to be inversely correlated to Urbach energy ( $r=-0.96$ for $E_{\text {Tauc }}$ vs $E_{\mathrm{U}}$ and -0.89 for $\left.E_{04} \mathrm{vs} E_{\mathrm{U}}\right)$, as is the Tauc parameter, although the latter not linearly $\left(r=-0.82\right.$ and $r_{\mathrm{s}}=-0.93$ for $B^{1 / 2}$ vs $\left.E_{\mathrm{U}}\right)$ (Figure 9). This interrelationship between band gap and disorder parameters is typical for amorphous semiconductor materials such as amorphous hydrogenated silicon [69,72].

\subsection{Charge Transport Properties}

Lastly, we turn to the charge transport response parameters, electrical resistivity $(\rho)$, field-dependent mobility $\left(\mu_{\mathrm{F}}, 0.1 \mathrm{MV} / \mathrm{cm}\right)$, and charge carrier concentration $(n)$. We have only performed a statistical analysis of effects on the electrical resistivity response; due to the nature of the electrical measurements (i.e., the possibility of low-field dielectric breakdown or inability to do a proper space-charge-limited current analysis), $\mu_{\mathrm{F}}$ and $n$ could only be reliably determined for a subset of samples and these data sets are therefore missing a relatively high number of data points. As can be seen from Figure S1 and Table S1, many main and interaction effects exhibit a relatively large magnitude in the case of resistivity, but only the partial flow rate effect is considered statistically significant. The temperature, power, and temperature*power effects are all on the threshold of significance $(0.05<P<0.1)$, with several other interaction effects not far behind. The electrical transport property responses exhibit the greatest error (typically an order of magnitude standard deviation; Table 2), and the poor statistics are compounded by the high number of missing data points. However, overall the effect profile suggests that the effects of growth conditions on charge transport properties may be quite complex. Because $\rho, \mu$, and $n$ are related via $\rho=1 / e n \mu$, we expect a correlation between variables. Indeed, there is a strong linear correlation between $\log \left(\mu_{\mathrm{F}}\right)$ and $\log (\rho)\left[r=-0.82\right.$; Figure 10(a)], and a strong linear correlation between $\log \left(\mu_{\mathrm{F}}\right)$ and $\log (n)[r=-0.77$; Figure 10(b)], but not between $\log (n)$ and $\log (\rho)[r=0.29$; Figure 10(c) $]$. In the latter case, the $\log (n)-\log (\rho)$ scatter plot appears to define a plane rather than a line. Indeed, when all three variables are plotted against one another in 3D space, this plane is clearly defined [Figure 10(d)] by four extremes: low $\mu\left(10^{-14}\right)$, high $n\left(10^{17}\right)$ and high $\rho\left(10^{16}\right)$; high $\mu\left(10^{-9}\right)$, low $n\left(10^{14}\right)$, and moderate $\rho\left(10^{13}\right)$; 
high $\mu\left(10^{-9}\right)$, moderate $n\left(10^{16}\right)$, and low $\rho\left(10^{12}\right)$; and moderate $\mu\left(10^{-11}\right)$, moderate $n\left(10^{15}\right)$, and moderate $\rho\left(10^{14}\right)$.

(a)

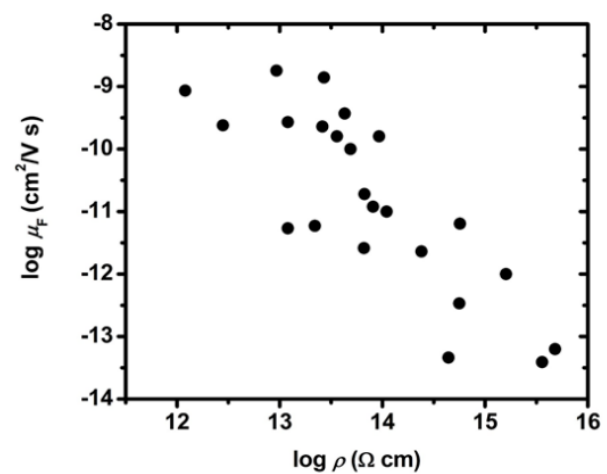

(c)

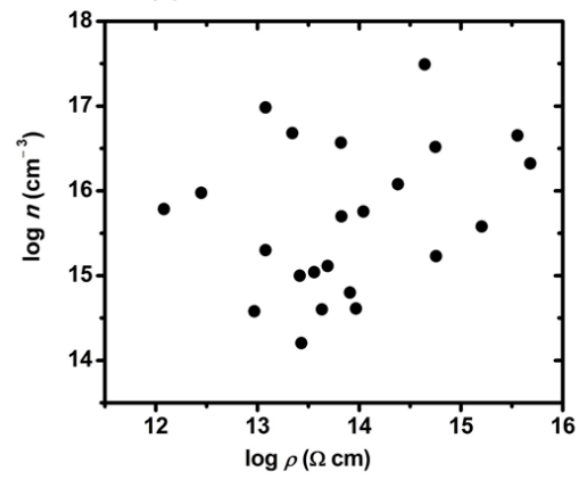

(b)

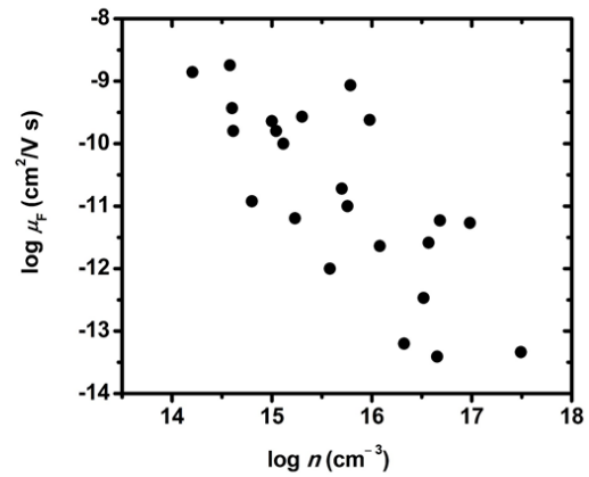

(d)

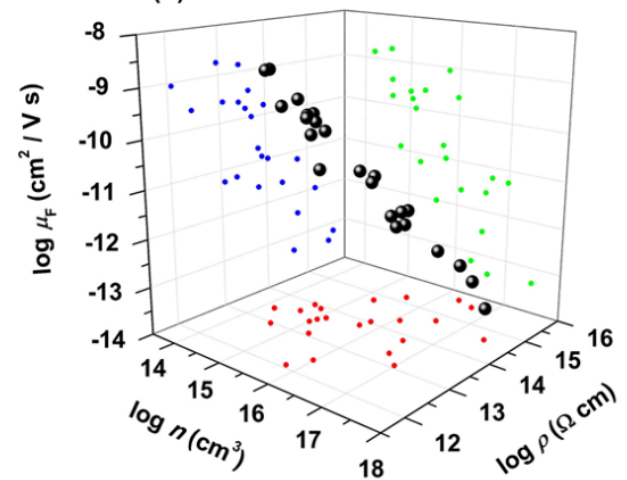

Figure 10. Correlations between (a) mobility $\left(\mu_{\mathrm{F}}\right.$, at $\left.0.1 \mathrm{MV} / \mathrm{cm}\right)$ and electrical resistivity $(\rho)$, (c) $\mu_{\mathrm{F}}$ and charge carrier concentration (n), (c) $n$ and $\rho$, and (d) all three variables (all plotted as logarithmic values). 


\subsection{Correlations between Chemical Composition and Material Properties}
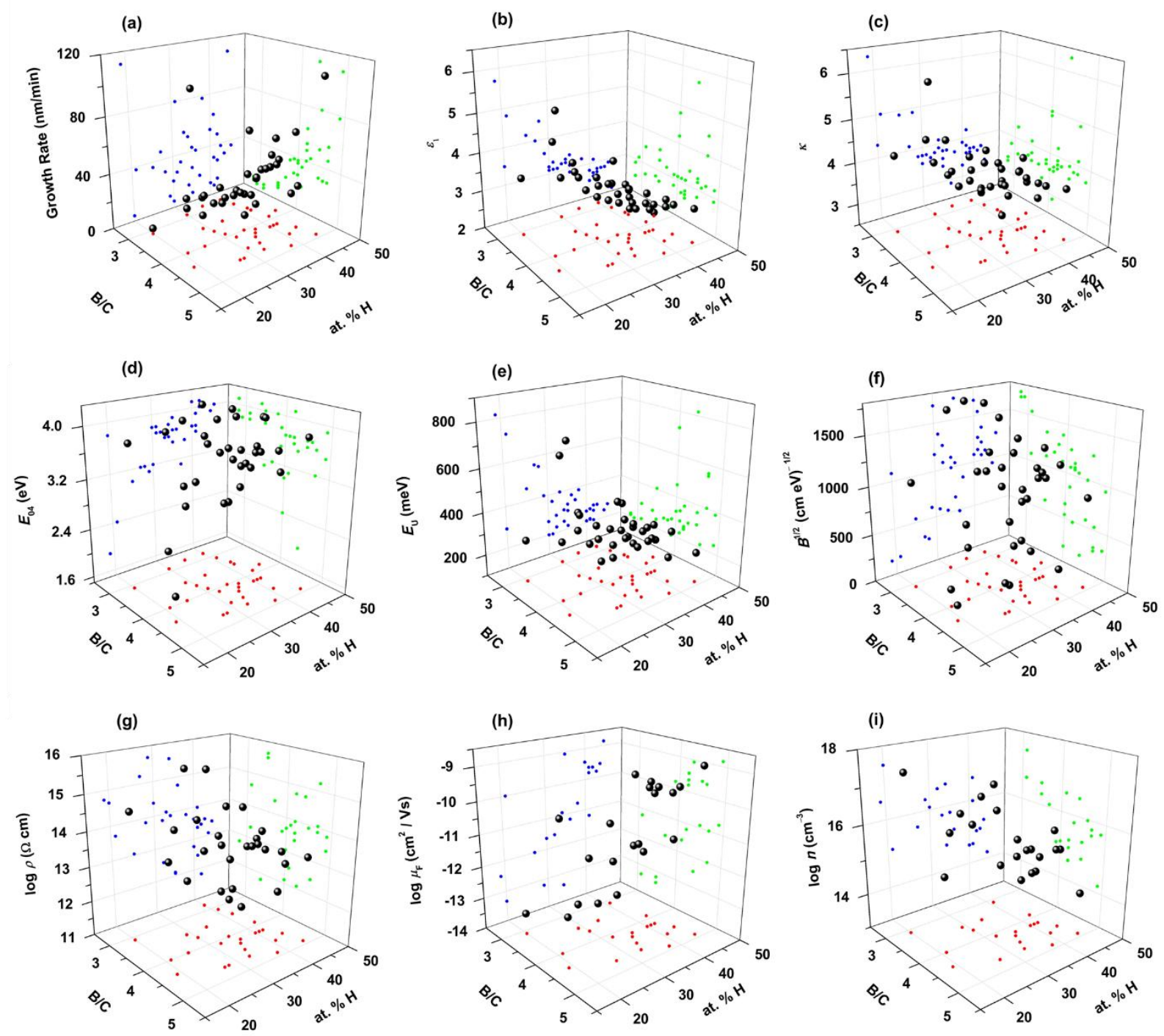

Figure 11. A series of properties in $\mathrm{a}-\mathrm{B}_{x} \mathrm{C}: \mathrm{H}_{y}$ films vs atomic concentration hydrogen and $\mathrm{B} / \mathrm{C}$ ratio: (a) growth rate, (b) high-frequency dielectric constant, $\varepsilon_{1}$, (c) low-frequency (total) dielectric constant, $\kappa$, (d) band gap, $E_{04}$, (e) Urbach energy, $E_{\mathrm{U}}$, (f) Tauc parameter, $B^{1 / 2}$, (g) electrical resistivity $(\log \rho$ ), (h) fielddependent mobility $\left(\log \mu_{\mathrm{F}}\right)$, and (i) charge carrier concentration $(\log n)$. 
(a)

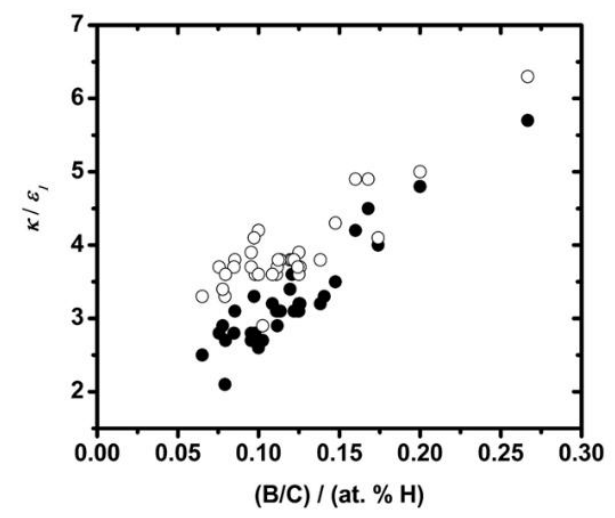

(c)

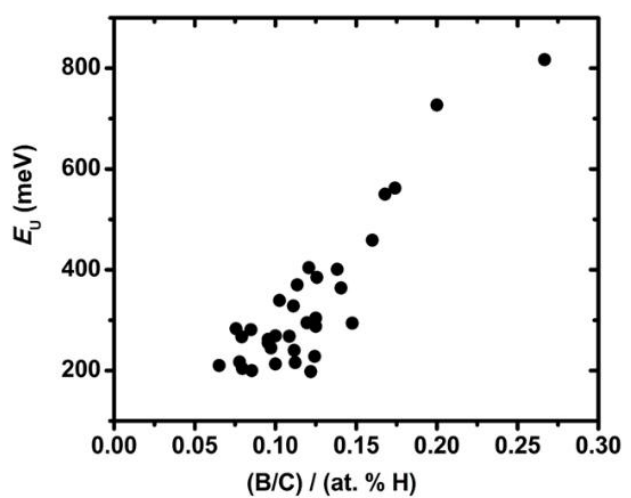

(b)

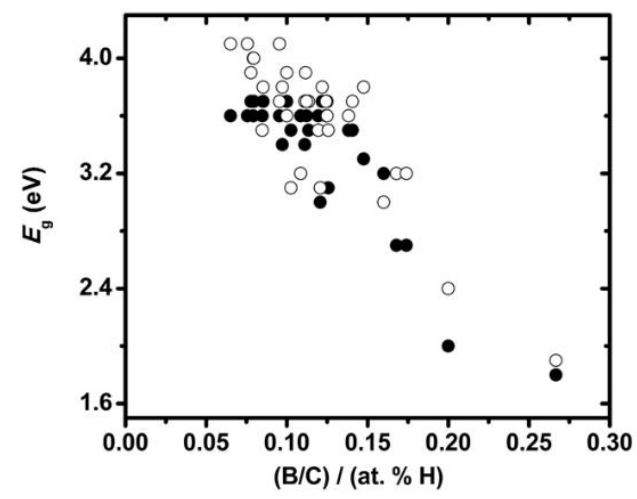

(d)

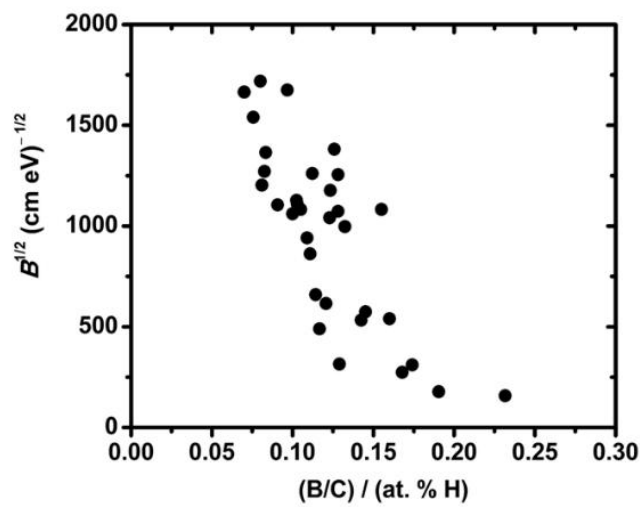

Figure 12. Optical and electronic properties $\left[\varepsilon_{1}(\bullet)\right.$ and $\kappa(\circ)(\mathrm{a}), E_{\mathrm{Tauc}}(\bullet)$ and $E_{04}(\circ)(\mathrm{b}), E_{\mathrm{U}}(\mathrm{c})$, and $B^{1 / 2}$ (d)] vs quotient of boron-to-carbon ratio and atomic concentration hydrogen. 
(a)

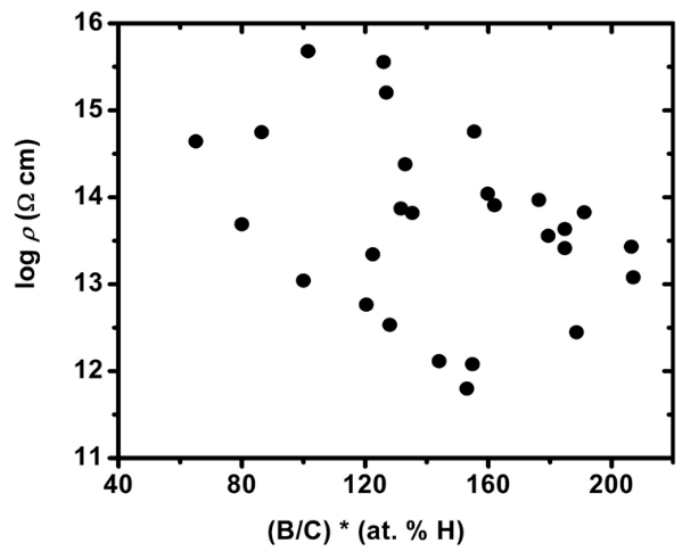

(b)

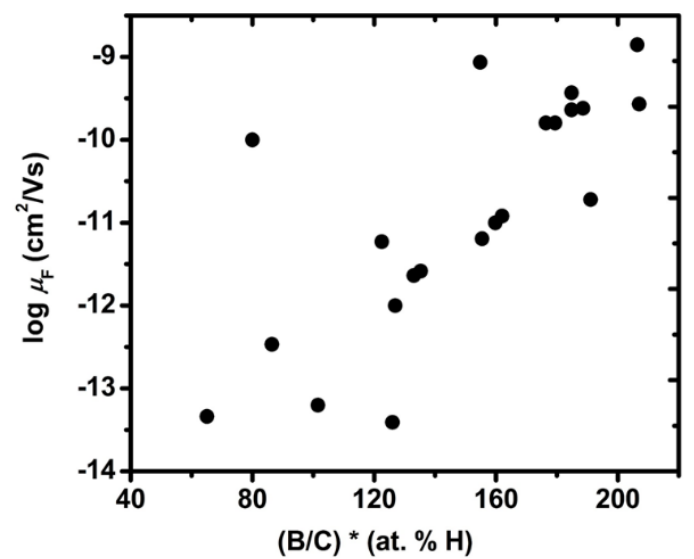

(c)

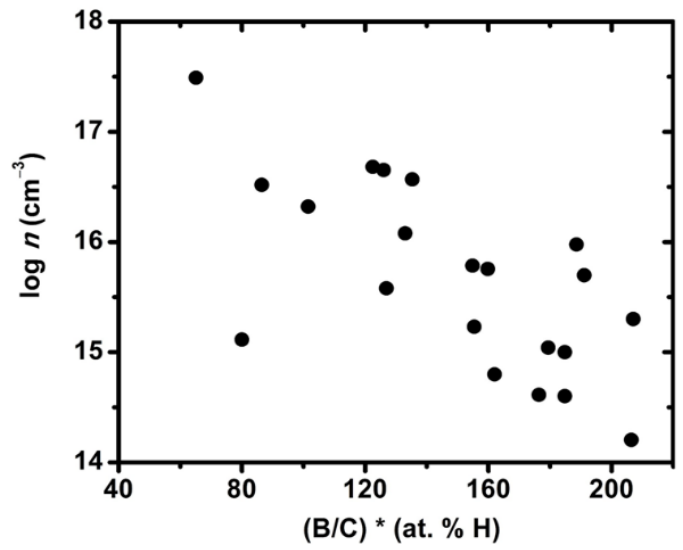

Figure 13. Electrical transport properties $\left[\log \rho(\mathrm{a}), \log \mu_{\mathrm{F}}(\mathrm{b})\right.$, and $\left.\log n(\mathrm{c})\right]$ vs the product of the boronto-carbon ratio and atomic concentration hydrogen.

Amorphous hydrogenated boron carbide $\left(a-\mathrm{B}_{x} \mathrm{C}: \mathrm{H}_{y}\right)$ is a complex material hypothesized to be composed of partially hydrogenated, partially cross-linked icosahedral carborane units and hydrocarbon groups, the precise configuration of which remains unknown [3,58]. Previously, we found that - despite the complexity of the local physical structure-hydrogen content could be used as a proxy for estimating 
and understanding many of the mechanical, chemical, electronic/optical, and charge transport properties of a- $\mathrm{B}_{x} \mathrm{C}: \mathrm{H}_{y}$ [58]. The current study highlights another structural feature quite independent from at.\% $\mathrm{H}$ $\left[\left(r=0.03\right.\right.$; Figure 5(c)] that also contributes to defining $\mathrm{a}-\mathrm{B}_{x} \mathrm{C}: \mathrm{H}_{y}$ material properties: the $\mathrm{B} / \mathrm{C}$ ratio. We have plotted a series of properties as a function of both at.\% $\mathrm{H}$ and $\mathrm{B} / \mathrm{C}$ ratio (Figure 11), and contrast the associated Pearson correlation coefficients in Table 4. The majority of the properties demonstrate a strong correlation with at.\% $\mathrm{H}$ and a weak to moderate correlation with $\mathrm{B} / \mathrm{C}$ ratio. The most pronounced exception - other than the growth rate, which is strongly correlated to $\mathrm{B} / \mathrm{C}$ ratio as previously discussedis the $B^{1 / 2}$ parameter, which demonstrates a stronger correlation with $\mathrm{B} / \mathrm{C}(r=-0.68)$ than with at. $\% \mathrm{H}(r$ $=0.50)$. For both $\mu_{\mathrm{F}}$ and $n$, the correlations with at. $\% \mathrm{H}$ and $\mathrm{B} / \mathrm{C}$ are of comparable magnitude. For some properties, scatter plots point to a correlation with $\mathrm{B} / \mathrm{C}$ ratio, although not necessarily a linear one. For example, the $\varepsilon_{1}-\mathrm{B} / \mathrm{C}$ [Figure 11(b)] and $E_{\mathrm{U}}-\mathrm{B} / \mathrm{C}$ [Figure 11(e)] scatter plots appear to define triangular planes, seemingly begging for a third dimension. Another notable observation lies in the sign of the correlation coefficients: for $E, H, \varepsilon_{1}, \kappa, \kappa-\varepsilon_{1}, E_{\mathrm{Tau}} / E_{04}, E_{\mathrm{U}}$, and $B^{1 / 2}$, the correlation coefficients with at.\% $\mathrm{H}$ and $\mathrm{B} / \mathrm{C}$ are of opposite sign; however for $\mu_{\mathrm{F}}$ and $n$, they are of the same sign. Thus, as can be observed in Figure $11, \varepsilon_{1}$, for example, is minimized at high at. $\% \mathrm{H}$ but low $\mathrm{B} / \mathrm{C}$, while $\mu_{\mathrm{F}}$ is maximized at high at. $\% \mathrm{H}$ and high $\mathrm{B} / \mathrm{C}$. To investigate a possible interaction between the at.\% $\mathrm{H}$ and $\mathrm{B} / \mathrm{C}$ variables, we have defined two new parameters: the product and quotient of the $\mathrm{B} / \mathrm{C}$ ratio and the at.\% $\mathrm{H}$. From Table 4 , we see that indeed $\varepsilon_{1}, \kappa, E_{\mathrm{Tauc}} / E_{04}, E_{\mathrm{U}}$, and $B^{1 / 2}$ are all better correlated with the combined (B/C)/at. $\% \mathrm{H}$ parameter than the individual parameters, while $\mu_{\mathrm{F}}$ and $n$ are better correlated with the combined $(\mathrm{B} / \mathrm{C}) *$ at.\% $\mathrm{H}$ parameter. These correlations are illustrated three dimensionally in Figure 11 and by scatter plots in Figures 12 and 13.

Table 4. Pearson correlation coefficients between $\mathrm{a}-\mathrm{B}_{x} \mathrm{C}: \mathrm{H}_{y}$ properties and $\mathrm{B} / \mathrm{C}$ and at. $\% \mathrm{H}$, as well as the product and quotient of the two (the strongest correlation for each property with at least $r>0.6$ is

\begin{tabular}{lcccc}
\multicolumn{5}{c}{ highlighted in bold). } \\
\hline & At.\%H & B/C & B/C $*$ At.\% H & B/C / At.\% H \\
\hline Gr. rate & 0.00 & $\mathbf{0 . 7 4}$ & 0.37 & 0.46 \\
At.\% O & 0.40 & -0.49 & 0.13 & $-\mathbf{0 . 6 5}$ \\
Density & $\mathbf{- 0 . 8 4}$ & 0.11 & -0.64 & 0.81 \\
$\boldsymbol{E}$ & $\mathbf{- 0 . 9 7}$ & 0.26 & -0.86 & 0.92 \\
$\boldsymbol{H}$ & $\mathbf{- 0 . 9 5}$ & 0.28 & -0.84 & 0.92 \\
$\boldsymbol{\varepsilon}_{\mathbf{1}}$ & -0.83 & 0.27 & -0.58 & $\mathbf{0 . 9 2}$ \\
$\boldsymbol{\kappa}$ & -0.68 & 0.24 & -0.47 & $\mathbf{0 . 8 3}$ \\
$\boldsymbol{\kappa}-\boldsymbol{\varepsilon}_{\mathbf{1}}$ & 0.56 & -0.14 & 0.40 & -0.49 \\
$\boldsymbol{E}_{\text {Tauc }}$ & 0.69 & -0.27 & 0.47 & $\mathbf{- 0 . 8 4}$ \\
$\boldsymbol{E}_{\mathbf{0 4}}$ & 0.69 & -0.32 & 0.41 & $\mathbf{- 0 . 8 2}$ \\
$\boldsymbol{E}_{\mathbf{U}}$ & -0.67 & 0.40 & -0.39 & $\mathbf{0 . 8 7}$ \\
$\boldsymbol{B}_{1 / 2}$ & 0.50 & -0.68 & 0.07 & $\mathbf{- 0 . 7 9}$ \\
$\boldsymbol{\rho}$ & -0.44 & 0.00 & -0.33 & 0.37 \\
$\boldsymbol{\mu}_{\mathrm{F}}$ & 0.67 & 0.54 & $\mathbf{0 . 7 5}$ & -0.35 \\
$\boldsymbol{n}$ & -0.55 & -0.60 & $-\mathbf{0 . 6 8}$ & 0.23 \\
\hline
\end{tabular}


The correlation between $\mathrm{B} / \mathrm{C}$ ratio and material properties suggests that carbon content presents an influence distinct from that of hydrogen content, whose role was previously rationalized primarily in terms of its effect on coordination number and mass/electron density. For $\varepsilon_{1}, \kappa, E_{\mathrm{Taud}} / E_{04}$, and $E_{\mathrm{U}}$, although $\mathrm{B} / \mathrm{C}$ has a moderate effect, the effect of $\mathrm{H}$ is clearly dominant. For $B^{1 / 2}$, the strong correlation to $\mathrm{B} / \mathrm{C}$ ratio may speak to the influence of $\mathrm{C}$ on the density of states features which contribute specifically to the $B^{1 / 2}$ parameter $[69,71,73]$. Overall, understanding the chemical environment of $\mathrm{C}$ in a- $\mathrm{B}_{x} \mathrm{C}: \mathrm{H}_{y}$, and ultimately its role in defining electronic structure is a nontrivial problem $[3,58]$ that will require further investigation of both an experimental and theoretical nature.

The fact that the electrical transport properties $\left(\rho, \mu_{\mathrm{F}}\right.$, and $\left.n\right)$ do not show the same behavior as the electronic structure properties $\left(E_{\mathrm{g}}, E_{\mathrm{U}}, B^{1 / 2}\right)$ was surprising to us, as we had originally hypothesized that we might see a strong correlation between, for example, mobility and band tail width - as parametrized by Urbach energy — as has been observed in a-Si:H and related materials and typically interpreted in the context of a multiple trapping model [74-76]. This result suggests that the chemical and electronic structure factors controlling charge transport are more nuanced than can be described by a simple univariate linear correlation model or basic multiple trapping model, further analysis of which is beyond the scope of this work.

\subsection{Property Optimization}

In terms of optimization of properties through controlling growth conditions, some comments can be made. We have concluded that hydrogen and density are primarily controlled by growth temperature and power, while $\mathrm{B} / \mathrm{C}$ ratio is primarily controlled by power, pressure, and the power*pressure interaction, with temperature and partial flow rate as secondary influences. The $\mathrm{B} / \mathrm{C}$ ratio appears to be related to growth rate, and to depend on a very similar set of process parameters, which also likely include weaker contributions from total/partial flow rate as well as interactions between pressure and flow rate. The at.\% $\mathrm{H}$ and $\mathrm{B} / \mathrm{C}$ ratio appear to not be correlated to each other at all, which is of interest as one might predict a correlation between at.\% $\mathrm{C}$ and at.\% $\mathrm{H}$ associated with hydrocarbon content as is typically observed in a$\mathrm{C}: \mathrm{H}$ and a-SiC:H $[71,77,78]$. As such, these may be treated as independent variables in modeling other material properties.

Many of the optical/electronic properties $\left(\varepsilon_{1}, \kappa, E_{\mathrm{g}}\right.$, and $\left.E_{\mathrm{U}}\right)$ are most strongly affected by growth temperature and most strongly correlated to at. $\mathrm{H}$, which is also most strongly affected by growth temperature. However, these same properties also show a dependence on power and pressure (including importantly the power*pressure interaction), as well as a weaker correlation to $\mathrm{B} / \mathrm{C}$ ratio, which is in turn more strongly influenced by power and pressure than by temperature. Thus, while growth temperature clearly plays a dominant role in determining material properties, power, pressure, and total/partial flow 
rates, as well as their interactions, also play a non-negligible role. Because the latter conditions were not varied in our previous work investigating the effects of power and temperature [58], their role- and the role of $\mathrm{C}$ - was not evident from the results. Regarding interactions, we observe that interaction effects between power, pressure, and total/partial flow rate are significant in a number of cases, but interaction effects involving temperature are weak or nonexistent, with the exception of a few instances including effects on $\kappa-\varepsilon_{1}$ and $\rho$. It appears therefore that temperature can be applied as a mostly independent 'knob' to tune material properties, while the remaining properties should be varied in combination, keeping in mind their interactions. Flow rate and partial flow rate, as well as their associated interactions generally exhibit weak effects that are not statistically significant. This may highlight an experiment design flaw more than the insignificance of these process parameters. Temperature, power, and pressure were all varied across a wide range, whereas flow rate and partial flow rate, in retrospect, may not have been varied across a wide enough range to truly capture their influence. Varying partial flow rate from 0.1 to 0.5 is a reasonably wide gap, but from 0.1 to 1 may have been a better choice. In the case of total flow rate, a range of 50 to $100 \mathrm{sccm}$ was almost certainly too small, and a range of 50 to $500 \mathrm{sccm}$, for example, may have been a better choice. Exploring these and even greater ranges would therefore be an appropriate subject for future investigations.

The overall low dielectric constant, high hardness and Young's modulus, and high electrical resistivity of the $\mathrm{a}-\mathrm{B}_{x} \mathrm{C}: \mathrm{H}_{y}$ films is promising toward their use as low- $\kappa$ dielectrics. The process-parameter analysis suggests pathways for optimizing $\mathrm{a}-\mathrm{B}_{x} \mathrm{C}: \mathrm{H}_{y}$ films for this application, specifically by applying low growth temperature, either at high power and high pressure or at low power and low pressure. Films grown using the first set of conditions (N15, N23, and N31) yielded on average values for $\varepsilon_{1}, \kappa$, and $\kappa-\varepsilon_{1}$ of 2.4, 3.1, and 0.7, respectively, while films grown using the latter set of conditions (N1, N9, N17, and $\mathrm{N} 25)$ yielded on average values for $\varepsilon_{1}, \kappa$, and $\kappa-\varepsilon_{1}$ of 2.6, 3.7, and 1.1, respectively. Because high power and high pressure growth conditions lead to higher electrical resistivities (i.e., lower leakage currents), and minimize the $\kappa-\varepsilon_{1}$ contribution, these may be more favorable. In addition, although low temperatures minimize the $\varepsilon_{1}$ value, they also increase the $\kappa-\varepsilon_{1}$ contribution and decrease $\rho$, which suggests that a slightly higher temperature may be more optimal. Finally, a combination of high flow rate and high partial flow rate may prove beneficial in minimizing the $\kappa-\varepsilon_{1}$ contribution, and exploring conditions beyond those applied in the present work could be worthwhile.

For semiconductor applications where charge carrier mobility is important, such as neutron detection [14], we have found that mobility is maximized with high at. $\% \mathrm{H}$ and $\mathrm{B} / \mathrm{C}$ ratio, parameters which are optimized at low temperature, low power, and low pressure growth conditions. Low pressure conditions, combined with high partial precursor flow rates, would also be optimal in producing films for neutron detection as these are required for the high growth rates needed to produce sufficiently thick films. In a 
previous publication [58], we observed a reversal in the dependency of electrical resistivity on at.\% $\mathrm{H}$ at moderate $\mathrm{H}$ concentrations (25-35\%), attributed to a possible change in dominant transport mechanism. In this previous study, resistivity was actually at its lowest (and mobility presumably at its highest) at very low $\mathrm{H}$ concentrations $(<20 \%)$. Because the majority of the films in the present study exhibit higher H concentrations, with none below $20 \%$, this reversal is not clearly apparent in the data. Therefore, we note that mobility can also apparently be maximized at high temperature/high power conditions, provided the temperature be suitably high $\left(>450{ }^{\circ} \mathrm{C}\right)$, even though this was not evident from the current study as these conditions were not sufficiently explored. On a related note, post-deposition annealing is also known to have an effect on $\mathrm{a}-\mathrm{B}_{x} \mathrm{C}: \mathrm{H}_{y}$ properties [57], and-although beyond the scope of the present study — is another important area for more detailed investigation.

\section{SUMMARY}

Through a multiresponse $2^{5}$ full factorial analysis of a- $\mathrm{B}_{x} \mathrm{C}: \mathrm{H}_{y}$ films grown by PECVD from orthocarborane, we have investigated the influence of five process parameters (growth temperature, RF power, pressure, total flow rate, and precursor partial flow rate) on a wide range of material properties. Thin-film properties were found to vary quite widely, within similar ranges as previously observed [58], with growth rate ranging from $1-112 \mathrm{~nm} / \mathrm{min}, \mathrm{B} / \mathrm{C}$ ratio from $2.8-4.9$, atomic concentration oxygen (at.\% $\mathrm{O}$ ) from $0-12 \%$ (average of $4 \%$ ), atomic concentration hydrogen (at.\% $\mathrm{H}$ ) from $19-46 \%$, Young's modulus $(E)$ from 9-281 GPa, hardness $(H)$ from 1-26 GPa, high-frequency dielectric constant $\left(\varepsilon_{1}\right)$ from 1.7-4.8, low-frequency (total) dielectric constant $(\kappa)$ from 2.4-5.0, band gap $\left(E_{04}\right)$ from 1.9-4.1 eV, Urbach energy $\left(E_{\mathrm{U}}\right)$ from $200-800 \mathrm{meV}$, Tauc parameter $\left(B^{1 / 2}\right)$ from $200-2200 \mathrm{~cm}^{-1 / 2} \cdot \mathrm{eV}^{-1 / 2}$, electrical resistivity $(\rho)$ from $10^{11}-10^{15} \Omega \cdot \mathrm{cm}$, field-dependent mobility $\left(\mu_{\mathrm{F}}\right.$ at $0.1 \mathrm{MV} / \mathrm{cm}$ ) from $10^{-9}-10^{-14} \mathrm{~cm}^{2} / \mathrm{V} \cdot \mathrm{s}$, and charge carrier concentration $(n)$ from $10^{14}-10^{17} \mathrm{~cm}^{-3}$.

Growth rate is most strongly influenced by pressure followed by precursor partial pressure, with high growth rates upwards of $100 \mathrm{~nm} / \mathrm{min}$ achieved at low pressures and high precursor dilutions, and rates on the order of $1 \mathrm{~nm} / \mathrm{min}$ for the opposite conditions. Hydrogen and density, as previously observed, are primarily controlled by growth temperature and power, while the $\mathrm{B} / \mathrm{C}$ ratio is primarily controlled by power, pressure, and the power*pressure interaction, with a strong correlation to growth rate and the factors influencing growth rate. High temperature and power conditions lead to hard, hydrogen-poor, high-density, low-porosity films, and vice versa. Dielectric and electronic structure properties $\left(\varepsilon_{1}, \kappa\right.$, $E_{\mathrm{Tau}} / E_{04}$, and $\left.E_{\mathrm{U}}\right)$ are found to correlate most strongly with at.\% $\mathrm{H}$, but also to some extent with $\mathrm{B} / \mathrm{C}$ ratio, and are influenced accordingly by growth conditions, showing a dominant effect from temperature, and secondary effect from the power*pressure interaction. The electrical properties also appear to be moderately correlated with at. $\% \mathrm{H}$ and $\mathrm{B} / \mathrm{C}$ ratio, but not in the same way as the electronic structure 
parameters, and thus no straightforward correlation between electronic structure and charge transport is observed.

Overall, the results of the $2^{5}$ full factorial analysis give insight into the a- $\mathrm{B}_{x} \mathrm{C}: \mathrm{H}_{y}$ film growth process, demonstrate the extreme tunability of this material, and direct us to the ranges of PECVD parameter space optical for producing films with properties needed for low- $\kappa$ dielectric, neutron detection, and other nextgeneration applications.

\section{ACKNOWLEDGMENTS}

The authors would like to thank Cory Hoshor for discussions regarding correlation analysis. We gratefully acknowledge Intel Corporation (contract no. 2012-IN-2313) and the Defense Threat Reduction Agency (grant no. HDTRA1-10-1-0092) for financial support of this research.

\section{REFERENCES}

[1] National Science and Technology Council, Materials Genome Initiative for Global Competitiveness, 2011, http://www.whitehouse.gov/sites/default/files/microsites/ostp/materials_genome_initiativefinal.pdf, retrieved August 17, 2015.

[2] J.J. De Pablo, B. Jones, C.L. Kovacs, V. Ozolins, A.P. Ramirez, The Materials Genome Initiative, the interplay of experiment, theory and computation, Curr. Opin. Solid State Mater. Sci. 18 (2014) 99-117. doi:10.1016/j.cossms.2014.02.003.

[3] M.M. Paquette, W. Li, M. Sky Driver, S. Karki, A.N. Caruso, N.A. Oyler, The local physical structure of amorphous hydrogenated boron carbide: insights from magic angle spinning solidstate NMR spectroscopy, J. Phys. Condens. Matter. 23 (2011) 435002. doi:10.1088/09538984/23/43/435002.

[4] D. Emin, Icosahedral boron-rich solids, Phys. Today. 40 (1987) 55-62. doi:http://dx.doi.org/10.1063/1.881112.

[5] M.M. Balakrishnarajan, P.D. Pancharatna, R. Hoffmann, Structure and bonding in boron carbide: The invincibility of imperfections, New J. Chem. 31 (2007) 473-485. doi:10.1039/b618493f.

[6] S.R. Elliott, Physics of Amorphous Materials, 2nd Ed., John Wiley \& Sons Inc., New York, 1990.

[7] R. Zallen, The Physics of Amorphous Solids, John Wiley \& Sons Inc., New York, 1998.

[8] S.J.L. Billinge, I. Levin, The problem with determining atomic structure at the nanoscale, Science. 316 (2007) 561-565. doi:10.1126/science.1135080.

[9] P.G. Debenedetti, F.H. Stillinger, Supercooled liquids and the glass transition, Nature. 410 (2001) 259-267. doi:10.1038/35065704. 
[10] H. Greuner, M. Balden, B. Boeswirth, H. Bolt, R. Gadow, P. Grigull, et al., Evaluation of vacuum plasma-sprayed boron carbide protection for the stainless steel first wall of WENDELSTEIN 7-X, J. Nucl. Mater. 329-333 (2004) 849-854. doi:10.1016/j.jnucmat.2004.04.214.

[11] O.I. Buzhinskij, V.A. Barsuk, V.G. Otroshchenko, Renewable boron carbide coating in plasma shots of tokamak T11-M, J. Nucl. Mater. 390-391 (2009) 996-999. doi:10.1016/j.jnucmat.2009.01.261.

[12] G. Gervino, M. Balma, D. Devona, A. Lavagno, C. Palmisano, L. Zamprotta, et al., Preliminary results of a new boron coated neutron detector, Nucl. Instruments Methods Phys. Res. Sect. A. 718 (2013) 143-144. doi:10.1016/j.nima.2012.08.092.

[13] B.W. Robertson, S. Adenwalla, A. Harken, P. Welsch, J.I. Brand, P.A. Dowben, et al., A class of boron-rich solid-state neutron detectors, Appl. Phys. Lett. 80 (2002) 3644-3646. doi:10.1063/1.1477942.

[14] N. Hong, J. Mullins, K. Foreman, S. Adenwalla, Boron carbide based solid state neutron detectors: the effects of bias and time constant on detection efficiency, J. Phys. D. Appl. Phys. 43 (2010) 275101. doi:10.1088/0022-3727/43/27/275101.

[15] A.N. Caruso, The physics of solid-state neutron detector materials and geometries, J. Phys. Condens. Matter. 22 (2010) 443201. doi:10.1088/0953-8984/22/44/443201.

[16] P. Chaudhari, A. Singh, A. Topkar, R. Dusane, Fabrication and characterization of silicon based thermal neutron detector with hot wire chemical vapor deposited boron carbide converter, Nucl. Instruments Methods Phys. Res. Sect. A. 779 (2015) 33-38. doi:10.1016/j.nima.2015.01.043.

[17] L.M. Han, Y. Xu, J.Z. Xie, M.S. Zhou, S. Chooi, Use of boron carbide as an etch-stop and barrier layer for copper dual damascene metallization, US Patent 6,352,921 B1, 2002.

[18] T.-A. Chen, R. Meagley, K.P. O’Brien, M.D. Goodner, J. Powers, Forming chemical vapor depositable low dielectric constant layers, US Patent 7,029,723 B2, 2006.

[19] S.W. King, Dielectric Barrier, Etch Stop, and Metal Capping Materials for State of the Art and beyond Metal Interconnects, ECS J. Solid State Sci. Technol. 4 (2015) N3029-N3047. doi:10.1149/2.0051501jss.

[20] International Technology Roadmap for Semiconductors - Interconnect Chapter, 2013.

[21] S.W. King, H. Simka, D. Herr, H. Akinaga, M. Garner, Research Updates: The three M's (materials, metrology, and modeling) together pave the path to future nanoelectronic technologies, APL Mater. 1 (2013) 040701. doi:10.1063/1.4822437.

[22] S. Sasaki, M. Takeda, K. Yokoyama, T. Miura, T. Suzuki, H. Suematsu, et al., Thermoelectric properties of boron-carbide thin film and thin film based thermoelectric device fabricated by intense-pulsed ion beam evaporation, Sci. Technol. Adv. Mater. 6 (2005) 181-184. doi:10.1016/j.stam.2004.11.010. 
[23] N. Hong, M.A. Langell, J. Liu, O. Kizilkaya, S. Adenwalla, Ni doping of semiconducting boron carbide, J. Appl. Phys. 107 (2010) 024513. doi:10.1063/1.3284205.

[24] R.A. Keski-Kuha, G.M. Blumenstock, C.M. Fleetwood, D.-R. Schmitt, Effects of space exposure on ion-beam-deposited silicon-carbide and boron-carbide coatings, Appl. Opt. 37 (1998) 8038-42. doi:10.1364/AO.37.008038.

[25] Y. Chen, Y.-W. Chung, S.-Y. Li, Boron carbide and boron carbonitride thin films as protective coatings in ultra-high density hard disk drives, Surf. Coatings Technol. 200 (2006) 4072-4077. doi:10.1016/j.surfcoat.2005.02.164.

[26] H.-P. Chang, W.-R. Chen, H.-W. Chiang, C.-S. Chen, C. Li, Coated glass article and method for manufacturing same, US Patent 8,512,867 B2, 2013.

[27] H. Hu, J. Kong, Improved thermal performance of diamond-copper composites with boron carbide coating, J. Mater. Eng. Perform. 23 (2014) 651-657. doi:10.1007/s11665-013-0780-z.

[28] L. Vandenbulcke, G. Vuillard, Composition and structural changes of boron carbides deposited by chemical vapour deposition under various conditions of temperature and supersaturation, J. LessCommon Met. 82 (1981) 49-56. doi:10.1016/0022-5088(81)90196-X.

[29] U. Jansson, J.-O. Carlsson, B. Stridh, S. Soderberg, M. Olsson, Chemical vapour deposition of boron carbides I: phase and chemical composition, Thin Solid Films. 172 (1989) 81-93. doi:10.1016/0040-6090(89)90120-X.

[30] J.I. Oñate, A. García, V. Bellido, J.L. Viviente, Deposition of hydrogenated B-C thin films and their mechanical and chemical characterization, Surf. Coatings Technol. 49 (1991) 548-553. doi:10.1016/0257-8972(91)90115-D.

[31] C. Godet, L. Schmirgeld, L. Zuppiroli, G. Sardin, S. Gujrathi, K. Oxorn, Optical properties and chemical reactivity of hydrogenated amorphous boron thin films, J. Mater. Sci. 26 (1991) 64086418. doi:10.1007/BF02387822.

[32] S. V. Deshpande, E. Gulari, S.J. Harris, A.M. Weiner, Filament activated chemical vapor deposition of boron carbide coatings, Appl. Phys. Lett. 65 (1994) 1757-1759. doi:10.1063/1.112909.

[33] K. Shirai, S. Emura, S. Gonda, Y. Kumashiro, Infrared study of amorphous $B_{1-x} C_{x}$ films, J. Appl. Phys. 78 (1995) 3392-3400. doi:10.1063/1.359967.

[34] S.-H. Lin, B.J. Feldman, D. Li, Microhardness study of amorphous hydrogenated boron carbide deposited on a cathode substrate by plasma deposition, Appl. Phys. Lett. 69 (1996) 2373-2375. doi:10.1063/1.117641.

[35] T. Hu, L. Steihl, W. Rafaniello, T. Fawcett, D.D. Hawn, J.G. Mashall, et al., Structures and properties of disordered boron carbide coatings generated by magnetron sputtering, Thin Solid Films. 332 (1998) 80-86. doi:10.1016/S0040-6090(98)01019-0. 
[36] A.O. Sezer, J.I. Brand, Chemical vapor deposition of boron carbide, Mater. Sci. Eng. B. 79 (2001) 191-202. doi:10.1016/S0921-5107(00)00538-9.

[37] H. Suematsu, K. Kitajima, T. Suzuki, W. Jiang, K. Yatsui, K. Kurashima, et al., Preparation of polycrystalline boron carbide thin films at room temperature by pulsed ion-beam evaporation, Appl. Phys. Lett. 80 (2002) 1153-1155. doi:10.1063/1.1449539.

[38] L.G. Jacobsohn, R.D. Averitt, C.J. Wetteland, R.K. Schulze, M. Nastasi, L.L. Daemen, et al., Role of intericosahedral chains on the hardness of sputtered boron carbide films, Appl. Phys. Lett. 84 (2004) 4173-4175. doi:10.1063/1.1755841.

[39] M. Wu, J.D. Kiely, T. Klemmer, Y.-T. Hsia, K. Howard, Process-property relationship of boron carbide thin films by magnetron sputtering, Thin Solid Films. 449 (2004) 120-124. doi:10.1016/S0040-6090.

[40] H. Ahn, P. Cuong, K. Shin, K. Lee, Tribological behavior of sputtered boron carbide coatings and the influence of processing gas, Wear. 259 (2005) 807-813. doi:10.1016/j.wear.2005.02.096.

[41] M. Zhou, S. Wong, C. Ong, Q. Li, Microstructure and mechanical properties of $\mathrm{B}_{4} \mathrm{C}$ films deposited by ion beam sputtering, Thin Solid Films. 516 (2007) 336-339. doi:10.1016/j.tsf.2007.06.030.

[42] I. Caretti, R. Gago, J. Albella, I. Jiménez, Boron carbides formed by coevaporation of B and C atoms: Vapor reactivity, $\mathrm{B}_{x} \mathrm{C}_{1-x}$ composition, and bonding structure, Phys. Rev. B. 77 (2008) 174109. doi:10.1103/PhysRevB.77.174109.

[43] A.K. Suri, C. Subramanian, J.K. Sonber, T.S.R.Ch. Murthy, Synthesis and consolidation of boron carbide: a review, Int. Mater. Rev. 55 (2010) 4-40. doi:10.1179/095066009X12506721665211.

[44] H.A. Castillo, E. Restrepo-Parra, J.M. Vélez, W. de la Cruz, Substrate temperature influence on boron carbide coatings grown by the PLD technique, Surf. Coatings Technol. 205 (2011) 36073612. doi:10.1016/j.surfcoat.2010.12.043.

[45] P. Chaudhari, N. Meshram, A. Singh, A. Topkar, R. Dusane, Hot wire chemical vapour deposition (HWCVD) of boron carbide thin films from ortho-carborane for neutron detection application, Thin Solid Films. (2011) 4-7. doi:10.1016/j.tsf.2011.01.295.

[46] C. Pallier, J.-M. Leyssale, L.A. Truflandier, A.T. Bui, P. Weisbecker, C. Gervais, et al., Structure of an Amorphous Boron Carbide Film: An Experimental and Computational Approach, Chem. Mater. 25 (2013) 2618-2629. doi:10.1021/cm400847t.

[47] R. James, F.L. Pasquale, J.A. Kelber, Plasma-enhanced chemical vapor deposition of orthocarborane: structural insights and interaction with $\mathrm{Cu}$ overlayers., J. Phys. Condens. Matter. 25 (2013) 355004. doi:10.1088/0953-8984/25/35/355004.

[48] V.Kh. Alimov, D.B. Bogomolov, M.N. Churaeva, A.E. Gorodetsky, S.L. Kanashenko, A.I. Kanaev, et al., Characterization of a-B/C:H films deposited from different boron containing precursors, J. Nucl. Mater. 196-198 (1992) 670-675. doi:10.1016/S0022-3115(06)80120-0. 
[49] A.I. Kanaev, S.Yu. Rybakov, M.N. Churaeva, EPMA and ellipsometric characterization of PECVD boron-carbon films, Le J. Phys. IV. 3 (1993) 183-188. doi:10.1051/jp4:1993323.

[50] D. Byun, S.-D. Hwang, P.A. Dowben, F.K. Perkins, F. Filips, N.J. Ianno, Heterojunction fabrication by selective induced by synchrotron radiation area chemical vapor deposition, Appl. Phys. Lett. 64 (1994) 1968-1970. doi:10.1063/1.111758.

[51] V.M. Sharapov, S.V. Mirnov, S.A. Grashin, S.V. Lebedev, I.A. Kovan, A.V. Krasilnikov, et al., Boronization of Russian tokamaks from carborane precursors, J. Nucl. Mater. 220-222 (1995) 730-735. doi:10.1016/0022-3115(94)00575-3.

[52] D. Zhang, D.N. McIlroy, W.L. O’Brien, G. de Stasio, The chemical and morphological properties of boron-carbon alloys grown by plasma-enhanced chemical vapour deposition, J. Mater. Sci. 33 (1998) 4911-4915. doi:10.1023/A:1004422016254.

[53] D.N. McIlroy, S.-D. Hwang, K. Yang, N. Remmes, P.A. Dowben, A.A. Ahmad, et al., The incorporation of Nickel and Phosphorus dopants into Boron-Carbon alloy thin films, Appl. Phys. A Mater. Sci. Process. 67 (1998) 335-342. doi:10.1007/s003390050780.

[54] S. Adenwalla, P. Welsch, A. Harken, J.I. Brand, A. Sezer, B.W. Robertson, Boron carbide/nsilicon carbide heterojunction diodes, Appl. Phys. Lett. 79 (2001) 4357-4359. doi:10.1063/1.1426257.

[55] A.N. Caruso, R.B. Billa, S. Balaz, J.I. Brand, P.A. Dowben, The heteroisomeric diode, J. Phys. Condens. Matter. 16 (2004) L139-L146. doi:10.1088/0953-8984/16/10/L04.

[56] D.L. Schulz, A. Lutfurakhmanov, B. Mayo, J. Sandstrom, D. Bunzow, S.B. Qadri, et al., Characterization of $\mathrm{a}-\mathrm{B}_{5} \mathrm{C}: \mathrm{H}$ prepared by PECVD of orthocarborane: Results of preliminary FTIR and nuclear reaction analysis studies, J. Non. Cryst. Solids. 354 (2008) 2369-2371. doi:10.1016/j.jnoncrysol.2007.10.077.

[57] R.B. Billa, T. Hofmann, M. Schubert, B.W. Robertson, Annealing effects on the optical properties of semiconducting boron carbide, J. Appl. Phys. 106 (2009) 033515. doi:10.1063/1.3190679.

[58] B.J. Nordell, S. Karki, T.D. Nguyen, P. Rulis, A.N. Caruso, S.S. Purohit, et al., The Influence of Hydrogen on the Chemical, Mechanical, Optical/Electronic, and Electrical Transport Properties of Amorphous Hydrogenated Boron Carbide, J. Appl. Phys. 118 (2015) 035703. doi:10.1063/1.4927037.

[59] D.C. Montgomery, Design and Analysis of Experiments, 5th Ed., John Wiley \& Sons, New York, 2001.

[60] P.W. Bohn, R.C. Manz, A Multiresponse Factorial Study of Reactor Parameters in PlasmaEnhanced CVD Growth of Amorphous Silicon Nitride, J. Electrochem. Soc. Solid-State Sci. Technol. 132 (1985) 1981-1984. doi:10.1149/1.2114265.

[61] J.N. Johnson, A.J. Cunningham, A factorial analysis of the preparation and properties of a-C:H thin films, Diam. Relat. Mater. 6 (1997) 1000-1004. doi:10.1016/S0925-9635(96)00741-8. 
[62] S. Ghosh, P.K. Dutta, D.N. Bose, Neural network modeling of PECVD silicon nitride films, Mater. Sci. Semicond. Process. 2 (1999) 1-11. doi:10.1016/S1369-8001(98)00023-7.

[63] C.L. Keck, Electrical carrier mobility measurements of amorphous hydrogenated boron carbide using space-charge-limited current techniques, Thesis, University of Missouri-Kansas City, ProQuest, UMI Dissertations Publishing, 2015. 1591069.

[64] J.C. Blakesley, F.A. Castro, W. Kylberg, G.F.A. Dibb, C. Arantes, R. Valaski, et al., Towards reliable charge-mobility benchmark measurements for organic semiconductors, Org. Electron. 15 (2014) 1263-1272. doi:10.1016/j.orgel.2014.02.008.

[65] SAS 9.4 for Windows, copyright 2002-2012 by SAS Institute Inc., Cary, NC, USA.

[66] J.L. Myers, A.D. Well, R.F. Lorch, Research Design and Statistical Analysis, 3rd Ed., Routledge, New York, NY, 2010.

[67] H.P.W. Hey, B.G. Sluijk, D.G. Hemmes, Ion Bombardment: A Determining Factor in Plasma CVD, Solid State Technol. 33 (1990) 139-144.

[68] P.A. Kohl, Low-Dielectric Constant Insulators for Future Integrated Circuits and Packages, Annu. Rev. Chem. Biomol. Eng. 2 (2011) 379-401. doi:10.1146/annurev-chembioeng-061010-114137.

[69] A.R. Zanatta, I. Chambouleyron, Absorption edge, band tails, and disorder of amorphous semiconductors, Phys. Rev. B. Condens. Matter. 53 (1996) 3833-3836. doi:10.1103/PhysRevB.53.3833.

[70] A.R. Zanatta, M. Mulato, I. Chambouleyron, Exponential absorption edge and disorder in Column IV amorphous semiconductors, J. Appl. Phys. 84 (1998) 5184. doi:10.1063/1.368768.

[71] G. Ambrosone, D.K. Basa, U. Coscia, M. Fathallah, Study on the microstructural and overall disorder in hydrogenated amorphous silicon carbon films, J. Appl. Phys. 104 (2008) 123520. doi:10.1063/1.3042242.

[72] G.D. Cody, T. Tiedje, B. Abeles, B. Brooks, Y. Goldstein, Disorder and the Optical-Absorption Edge of Hydrogenated Amorphous Silicon, Phys. Rev. Lett. 47 (1981) 1480-1483. doi:10.1103/PhysRevLett.47.1480.

[73] B. Akaoglu, K. Sel, I. Atilgan, B. Katircioglu, Carbon content influence on the optical constants of hydrogenated amorphous silicon carbon alloys, Opt. Mater. 30 (2008) 1257-1267. doi:10.1016/j.optmat.2007.06.005.

[74] Q. Wang, H. Antoniadis, E.A. Schiff, S. Guha, Electron-drift-mobility measurements and exponential conduction-band tails in hydrogenated amorphous silicon-germanium alloys, Phys. Rev. B. 47 (1993) 9435-9448. doi:10.1103/PhysRevB.47.9435.

[75] Q. Gu, Q. Wang, E.A. Schiff, Y.M. Li, C.T. Malone, Hole drift mobility measurements in amorphous silicon-carbon alloys, J. Appl. Phys. 76 (1994) 2310-2315. doi:10.1063/1.358508. 
[76] D.S. Shen, S. Wagner, Transient photocurrent in hydrogenated amorphous silicon and implications for photodetector devices, J. Appl. Phys. 79 (1996) 794-801. doi:10.1063/1.360827.

[77] C. Casiraghi, A. Ferrari, J. Robertson, Raman spectroscopy of hydrogenated amorphous carbons, Phys. Rev. B. 72 (2005) 085401. doi:10.1103/PhysRevB.72.085401.

[78] D.K. Basa, G. Abbate, G. Ambrosone, U. Coscia, A. Marino, Spectroscopic ellipsometry study of hydrogenated amorphous silicon carbon alloy films deposited by plasma enhanced chemical vapor deposition, J. Appl. Phys. 107 (2010) 023502. doi:10.1063/1.3277016. 